\title{
An Analysis for the Qualitative Improvement of Education and Learning based on the Way of Learner Errors in Descriptive Questions
}

\author{
Michiko Tsubaki ${ }^{1 *}$, Wataru Ogawara ${ }^{1}$, Kenta Tanaka ${ }^{1}$ \\ ${ }^{1}$ The University of Electro-Communications, JAPAN \\ *CORRESPONDENCE: $₫$ tsubaki@se.uec.ac.jp
}

\begin{abstract}
This study proposes and examines an analytical method with the aim of improving the quality of education and learning by situating the answers to full descriptive questions in probability and statistics to make variables of learners' comprehension of learned content as answer characteristics, based on actual student mistakes. First, we proposed and examined a method for extracting answer characteristics from the answers to the questions in probability and statistics as variables. Second, we proposed a method for obtaining answer characteristics to accurately describe learners' comprehension of each problem and indicate learning and educational policies for learners to improve learning by using regression trees. In addition, the relationship between learners' general ability and answer characteristics was visualized in an item characteristic chart to indicate the general comprehension of the learners. Further, the relationship between learners' learning strategy and answer characteristics was structuralized using Bayesian network models, and effective learning strategies for both learners as a whole and individual learners were extracted and evaluated towards the qualitative improvement of their comprehension using probabilistic reasoning. Our findings showed that the effectiveness of a learning strategy varies with each concept treated in a given problem; with the degree of basical or applied answer characteristics, indicating that the required learning strategy varies according to a given learner's stage of learning. Moreover, the improvement of hours studying dispersion for both mid-term and final examinations was revealed as effective for a wide range of subjects.
\end{abstract}

Keywords: learning and education in probability and statistics, descriptive questions, extraction of answer characteristics, error analysis, Bayesian network analysis, probabilistic reasoning

\section{INTRODUCTION}

"Error analysis" is an analysis of how and why learners make an error, and has been applied in a wide range of fields, including simple questions involving four arithmetic operations. Rushton (2018) studied the effect of the teaching and learning mathematics through error analysis. Mathematics education pedagogy has relied on teachers, demonstrating correctly worked example exercises. However, in recent years, combining the use of correctly worked exercises with error analysis has led researchers to posit increased mathematical understanding. Durkin and Rittle-Johnson (2012) studied the effectiveness of using incorrect examples to support learning about decimal magnitude.

In addition, in the discipline of probability and statistics, various misconceptions exist, as concluded by Kahneman and Tversky (1982), Sulistyani (2019) showed that there were 4 stages of student errors in

Article History: Received 17 February $2020 \bullet$ Revised 2 March $2020 \bullet$ Accepted 2 March 2020

(C) 2020 by the authors; licensee Modestum Ltd., UK. Open Access terms of the Creative Commons Attribution 4.0 International License (http://creativecommons.org/licenses/by/4.0/) apply. The license permits unrestricted use, distribution, and reproduction in any medium, on the condition that users give exact credit to the original author(s) and the source, provide a link to the Creative Commons license, and indicate if they made any changes. 
inferential statistics. 1) Errors in comprehension occurred because students could not read statistics tables or read outputs in the questions. 2) Transformation errors occurred because students were not appropriate in applying/selecting the type of test statistics used or writing hypotheses. 3) Process skill errors occurred because students were less careful in calculating and inability to interpret the results of calculations. 4) Errors in the encoding stage occurred because students did not answer correctly or inappropriately in drawing conclusions in hypothesis testing. These results point to properties peculiar to the content of learning in the fields of probability and statistics, suggesting a possible trend in the ways learners of probability and statistics make errors. It would therefore be useful to analyze the information related to the learning experiences of other students who made errors in a similar fashion.

Accordingly, this study proposes the extraction of answer characteristics as variables, based on the forms of error that characterize differences in the degree of learners' comprehension using full descriptive questions related to probability and statistics. Then, using these variables, we perform a regression tree analysis on learners' comprehension of the study content for each problem, as well as an analysis of an item characteristic chart to estimate general comprehension, and a relational analysis between the comprehension and study strategy using Bayesian networks. In so doing, furthermore we propose a method for extracting effective learning policies or learning strategies for learners as a whole, as well as individual learners, through a probabilistic reasoning based on Bayesian networks.

\section{OVERVIEW OF DATA FOR ANALYSIS}

This study used students' mid-term and final examination results in a "Probability and Statistics" course offered to sophomore students enrolled in M Engineering Division in J Department at D University, as well as the results of a questionnaire survey on learning situation that was administered during the course to collect data for analysis upon students' consent. One hundred-four students took the mid-term examination, and 99 took the final examination. Of all students who took both examinations and answered the questionnaire survey, consent for use of the data was obtained from 89; these data were then analyzed for this study. In a Probability and Statistics course, the key concepts and items based on the textbook were explained and exercises were implemented during the lesson. Participants received feedback during the exercises through which they were learning probability theory and conducting statistical estimation and testing.

\section{Questionnaire Survey Design}

The questionnaire survey was designed to meet the goal of this study based on items concerning selfefficacy, intrinsic value, cognitive strategy and self-regulation, in accordance with the approach adopted by Pintrich and De Groot (1990), to examine the level of learning situation, by such that the questionnaire items conformed to purpose of the study. Further, questionnaire items concerning study habit, study time, and the type of materials used for study were also created as important measures in the study of probability and statistics (Table 1). 
Table 1. Items in the Questionnaire Survey

\begin{tabular}{|c|c|c|}
\hline Name & Description & Answer form \\
\hline Self-efficacy: Useful & $\begin{array}{l}\text { I think I can appropriately use what I learn in the } \\
\text { probability and statistics class }\end{array}$ & \multirow{16}{*}{$\begin{array}{l}\text { 5-point scale } \\
\text { assessment } \\
\text { (1: Strongly disagree, } \\
\text { 2: Disagree, } \\
\text { 3: Undecided, } \\
\text { 4: Agree } \\
\text { t 5: Strongly agree) }\end{array}$} \\
\hline $\begin{array}{l}\text { Self-efficacy: Within the scope of the } \\
\text { course }\end{array}$ & $\begin{array}{l}\text { I think I can solve the scope of the problems worked in } \\
\text { the class. }\end{array}$ & \\
\hline $\begin{array}{l}\text { Self-efficacy: Outside the scope of the } \\
\text { course }\end{array}$ & $\begin{array}{l}\text { I think I can understand content outside of the scope of } \\
\text { this class if I study it. }\end{array}$ & \\
\hline Intrinsic value: Important & $\begin{array}{l}\text { I think probability and statistics is an important subject } \\
\text { for me. }\end{array}$ & \\
\hline Intrinsic value: Interesting & I find probability and statistics interesting. & \\
\hline $\begin{array}{l}\text { Cognitive strategy: Understand in one's } \\
\text { own words }\end{array}$ & $\begin{array}{l}\text { I try to understand matters that strike me as important } \\
\text { by putting them into my own words. }\end{array}$ & \\
\hline $\begin{array}{l}\text { Cognitive strategy: Identification of } \\
\text { content }\end{array}$ & $\begin{array}{l}\text { I think about how to locate the study content within the } \\
\text { field of probability and statistics. }\end{array}$ & \\
\hline $\begin{array}{l}\text { Cognitive strategy: Association with } \\
\text { one's knowledge }\end{array}$ & $\begin{array}{l}\text { I try to make an association with my previous } \\
\text { knowledge when I study something new. }\end{array}$ & \\
\hline $\begin{array}{l}\text { Cognitive strategy: Repetitive learning } \\
\text { of key concepts }\end{array}$ & I repeatedly study concepts that seems important to me. & \\
\hline Self-regulation: Comprehension check & I confirm my comprehension of the study content. & \\
\hline Self-regulation: Self-directed learning & $\begin{array}{l}\text { I work exercises by my self without being required to do } \\
\text { so in class. }\end{array}$ & \\
\hline Self-regulation: Rereading & $\begin{array}{l}\text { When I read the textbook or a reference, I review what I } \\
\text { have already read. }\end{array}$ & \\
\hline Self-regulation: Uninterested topics & $\begin{array}{l}\text { I study hard even for a topic in which I am not } \\
\text { interested. }\end{array}$ & \\
\hline $\begin{array}{l}\text { Study habit: Daily preparation and } \\
\text { review }\end{array}$ & $\begin{array}{l}\text { I make it a daily rule to prepare for and review the } \\
\text { classwork in the probability and statistics course. }\end{array}$ & \\
\hline Study habit: Review before examination & $\begin{array}{l}\text { I attentively review what I have learned in the } \\
\text { probability and statistics course before an exam. }\end{array}$ & \\
\hline $\begin{array}{l}\text { Study habit: Study with similar } \\
\text { problems }\end{array}$ & $\begin{array}{l}\text { I work on problems that are similar to problems I had } \\
\text { difficulty solving in the probability and statistics course. }\end{array}$ & \\
\hline Study time: Central position & $\begin{array}{l}\text { Cumulative study time on the center of distribution } \\
\text { during the course }\end{array}$ & \multirow[t]{6}{*}{ Fill out numbers } \\
\hline Study time: Dispersion & $\begin{array}{l}\text { Cumulative study time on the dispersion of distribution } \\
\text { during the course. }\end{array}$ & \\
\hline Study time: Probability distribution & $\begin{array}{l}\text { Cumulative study time on probability distribution } \\
\text { during the course }\end{array}$ & \\
\hline Study time: Relation between variables & $\begin{array}{l}\text { Cumulative study time on the relation between } \\
\text { variables during the course }\end{array}$ & \\
\hline Study time: Statistical estimation & $\begin{array}{l}\text { Cumulative study time on statistical estimation during } \\
\text { the course }\end{array}$ & \\
\hline Study time: Statistical testing & $\begin{array}{l}\text { Cumulative study time on statistical testing during the } \\
\text { course }\end{array}$ & \\
\hline Prescribed textbook & Use of prescribed textbooks during study & \multirow{7}{*}{$\begin{array}{l}\text { Yes-no question (0: No } \\
\text {, 1: Yes) }\end{array}$} \\
\hline References: Probability and statistics & $\begin{array}{l}\text { Use of references on probability and statistics during } \\
\text { study }\end{array}$ & \\
\hline $\begin{array}{l}\text { References: Outside probability and } \\
\text { statistics }\end{array}$ & $\begin{array}{l}\text { Use of references on topics other than probability and } \\
\text { statistics during study }\end{array}$ & \\
\hline Web-based material & Use of web-based material during study & \\
\hline $\begin{array}{l}\text { Other course materials or materials } \\
\text { from other universities }\end{array}$ & $\begin{array}{l}\text { Use of other course materials or materials from other } \\
\text { universities during study }\end{array}$ & \\
\hline Video material & Use of e-Learning and video material during study & \\
\hline Others & Use of other materials during study & \\
\hline
\end{tabular}

\section{Problems in the Mid-term Examination}

The mid-term examination consisted of four full descriptive problems on the probability theories that students had learned in the first half of the course. Students could use a calculator during the examination, but were prohibited from bringing in textbooks or associated materials.

Figure 1 shows Problem 1 as an example of the problems provided as test items in the examination. Problem 1 is composed of questions associated with the mean, variance, and conditional probability based on the simultaneous probability distribution of 2 variables, and was worth 30 total points. As shown in Figure 
Problem 1: Suppose that the simultaneous probabilistic distribution of random variables $X, Y$ follows the table below.

\begin{tabular}{|c|c|c|c|c|}
\hline$X$ & 1 & 2 & 3 & $\begin{array}{c}\text { marginal } \\
\text { distribution }\end{array}$ \\
\hline 1 & 0.050 & 0.100 & 0.050 & 0.200 \\
\hline 2 & 0.075 & 0.150 & 0.075 & 0.300 \\
\hline 3 & 0.125 & 0.250 & 0.125 & 0.500 \\
\hline $\begin{array}{c}\text { marginal } \\
\text { distribution }\end{array}$ & 0.250 & 0.500 & 0.250 & 1.000 \\
\hline
\end{tabular}

(1) Are random variables $\mathrm{X}$ and $\mathrm{Y}$ independent or dependent?

State the answer while explaining the reason for it.

(2) Calculate the conditional distribution and conditional mean of $\mathrm{Y}$ given $\mathrm{X}=2$ (Round up to 3 decimal places).

(3) Calculate E $[\mathrm{XY}]$ (Round up to 3 decimal places).

(4) Calculate $\mathrm{V}[\mathrm{X}+\mathrm{Y}]$ (Round up to 3 decimal places).

Figure 1. Problem 1 In Mid-term Examination

\section{Problem 1}

(1) Lesd the maximum likelihood estimator of the parameter $\lambda$ based on sample variables $(\mathrm{X} 1, \mathrm{X} 2, \ldots, \mathrm{Xn})$ from the population that follow the Poisson distribution.

Note that the probability distribution of the Poisson distribution is expressed by the formula.

$$
f\left(x_{i} ; \lambda\right)=\frac{\lambda^{x_{i}} e^{-\lambda}}{x_{i} !}\left(x_{i}=0,1,2, \ldots\right)
$$

(2) Show that the maximum likelihood estimator led in (1) has the properties of (2-1) unbiasedness and (2-2) minimum variance and (2-3) consistency.

Figure 2. Problem 1 in the Final Examination

1, a simultaneous probability distribution table for two random variables is given, and the students must answer four questions.

Question (1) requires an assessment of whether two random variables are independent or dependent and a description of the reason for the judgment; a correct answer receives 5 points. Question (2) requires calculating the conditional distribution and the mean; a correct answer receives 10 points. Questions (3) and (4) require calculations of the expected values and for the product and the sum of the two random variables; correct answers receive 5 and 10 points each, respectively.

\section{Problems in the Final Examination}

The final examination consisted of four full descriptive problems on statistical estimation and testing, which students learned in the second half of the course. Figure 2 shows Problem 1 as an example. Problem 1 is associated with maximum likelihood estimation, a key concept in statistical estimation, and (1) requires drawing the maximum likelihood estimator of the parameter $\lambda$ in a Poisson distribution. A correct answer receives 10 points. Question (2-1) requires the student to prove the unbiasness of the estimator led in (1), question (2-2) requires proving its minimum variance; and question (2-3) requires the student to prove its consistency; 5 , 10, and 5 points are allocated to each question, respectively.

\section{SCORING MODEL IN THE EXAMINATION AND EXTRACTION OF ANSWER CHARACTERISTICS AS VARIABLES}

Here, the scoring system of the examination is examined and a method for making variables, which characterize the answers based on the mistakes students made when answering the full descriptive questions, is proposed. 


\section{Scoring Model for Full Descriptive Questions}

First, regarding the multiple-choice questions, suppose $p$ question items exist. Let $Y_{j}$ express the correctness or incorrectness of the question $j$. Further, suppose that $\boldsymbol{Y}$ is a vector which express the correctness or incorrectness of the entire problem in the examination. Then,

$$
\begin{aligned}
& Y=\left[Y_{1}, Y_{2}, \cdots, Y_{p}\right] \\
& Y_{j}=0 \text { (Incorrect in Question j), } 1 \text { (Correct in Question j) }
\end{aligned}
$$

and $\boldsymbol{Y}=\boldsymbol{y}$, which is obtained in the real examination, is named the item response data (Toyota, 2012). The score $S$ in the examination is expressed by the formula (3), where each $Y_{j}$ is multiplied by weight $W_{j}$ and is then totaled.

$$
S=\sum_{j=1}^{p} W_{j} Y_{j}
$$

$W_{j}$ was set by the creator of the test based on the importance of the content that is assessed in question $j$. In this scoring model, a learner's response is expressed by two values, which are correct or incorrect, for the test questions. For this reason, the difference in the comprehension of learners as they provide wrong answers (for example, the difference between a learner who arrives at an incorrect answer after working on the question and a learner who fails to arrive at an answer after working on the question), cannot be expressed in formulas (1) to (3).

Unlike this, the full descriptive problem includes questions that require indicating not only the result but also the calculation process or the writing of a proof, and is often evaluated in detail such that even if the answer is close to achieving full credit (or close to 0), some points may be deducted (or added). Thus, we consider that the scoring model for the full descriptive examination in which detailed scoring, such as pointdeduction or addition, can be successfully carried out.

The score for the question $\mathrm{i}$ ( $\mathrm{i}=1$ to $\mathrm{p}$ ), where learning content items $\mathrm{A} 1, \mathrm{~A} 2, \ldots$, or Aq are tested is expressed as $m_{1}, m_{2}, \ldots, m_{q}$, respectively, and in circumstances in which is a partial point deduction is made for content items $\mathrm{Ak}$, which is answered correctly, $d_{k}$ points are deducted, and where there is a partial point addition for content items Ak, which is answered incorrectly, $c_{k}$ points are added. Thus, $Y_{j}$ can be expressed as follows.

$$
Y_{j}=\left[Y_{j 11}, Y_{j 12}, Y_{j 13}, \cdots, Y_{j q 1}, Y_{j q 2}, Y_{j q 3}\right]
$$

$Y_{j k 1}: 1$ if the answer for $\mathrm{Ak}$ is correct, 0 if the answer is incorrect

$Y_{j k 2}: 1$ if there is a point deduction in the answer for $\mathrm{Ak}, 0$ if there is no point deduction

$Y_{j k 3}: 1$ if there is a point addition in the answer for $\mathrm{Ak}, 0$ if there is no point addition

and score $\mathrm{S}_{\mathrm{j}}$ for question $\mathrm{j}$ can be expressed as follows.

$$
S_{j}=\sum_{k=1}^{q}\left(m_{k} Y_{j k 1}-d_{k} Y_{j k 2}+c_{k} Y_{j k 3}\right)
$$

The multiple-choice test scoring model can be applied to a full descriptive test by expanding it into the full descriptive test scoring model, as shown in formula (5).

\section{Extraction of Answer Characteristics based on Mistakes in the Full Descriptive Test as Variables}

In this paper, each content item characterizing differences in the comprehension of learners is regarded as an answer characteristic for each question, and a method for expressing learner's answer characteristics is proposed and examined.

Figure 3 illustrates the concept of extracting answer characteristics. Suppose that a problem assesses the comprehension of study content A, which comprises 5 items-A1, A2, A3, A4, and A5, and answers from learners 1, 2, 3, and 4 are obtained. Learner 1 correctly answers A1 and A2, while learner 3 correctly answers all except A5. Further, suppose that learner 2 correctly answers all, while learner 4 incorrectly answers all. When these answers are obtained, the comprehension of learners 2 and 4 can be expressed by the correct or incorrect answer to the questions, whereas the comprehension of learners 1 and 3 reflects differences in their comprehension of A3 and A4. Further, the comprehension of learners 2 and 3 can be characterized by the 


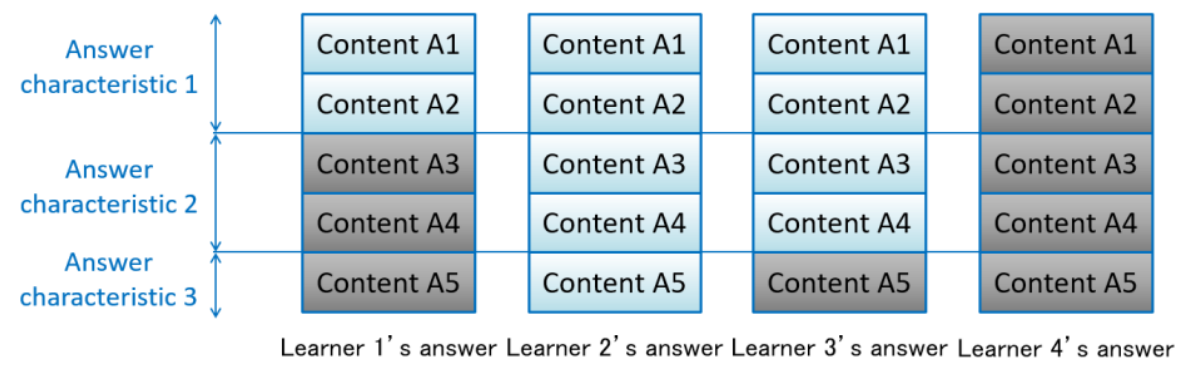

Figure 3. Conceptual Scheme for Extraction Of Answer Characteristics

Table 2. Expression Of Comprehension Via Answer Characteristic Variables

\begin{tabular}{lccc}
\hline & Answer characteristic B1 & Answer characteristic B2 & Answer characteristic B3 \\
\hline Learner 1 & 1 & 0 & 0 \\
\hline Learner 2 & 1 & 1 & 1 \\
\hline Learner 3 & 1 & 1 & 0 \\
\hline Learner 4 & 0 & 0 & 0 \\
\hline
\end{tabular}

When the random variables $\mathrm{X}$ and $\mathrm{Y}$ are independent, for all $(\mathrm{X}, \mathrm{Y}), \mathrm{P}(\mathrm{X}, \mathrm{Y})=\mathrm{P}(\mathrm{X}) \mathrm{P}(\mathrm{Y})$

From the table, when $\mathrm{X}=1$ and $\mathrm{Y}=1$,

$$
\begin{aligned}
& P(X=1, Y=1)=0.050 \\
& P(X=1) P(Y=1)=0.200 \times 0.250=0.050
\end{aligned}
$$

Thus, the formula is true.

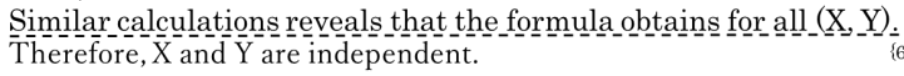

Figure 4. Model Answer to Problem 1-(1) in the Mid-term Examination

difference in their comprehension of A5. In other words, the learners' comprehension can be characterized by "the comprehension of A1 and A2," "comprehension of A3 and A4," and "comprehension of A5." Thus, making variables of these as the answer characteristics B1, B2, and B3, respectively, allows us to characterize learners' answers in turn, as shown in Table 2.

The procedure for extracting the answer characteristics is explained below. First, of all $n$ learners, suppose there are s learners who provided a partially false answer to question $j$ without leaving it blank, and are expressed as learner $i(=1, \ldots, s)$.

(i) Closely examine the answers of learner $i=1$, and let the characteristic Bk, which corresponds to each fallacy, be an answer characteristic extracted by $i=1$.

(ii) Closely examine the answers of learners $i(=2, \ldots, \mathrm{s})$. (a) When the answers of learner $i$ can be expressed by the answer characteristic variables extracted until learner $i-1$, express the answers of the learner $i$ using the answer characteristic variables obtained by learner $i-1$.

(b) When the answers of learner $i$ cannot be expressed by the answer characteristic variables extracted until learner $i-1$, add a new answer characteristic variable to express the answer of learner $i$.

(iii) Repeat step (ii) until $i=\mathrm{s}$.

(iv) Express the answers from $i=1$ to $i=s$ in terms of answer characteristic variables $\mathrm{B} 1$ to $\mathrm{Br}$.

(v) For the remaining $n-s$ learners, set a value of 0 for all answer characteristic variables for the learners who did not answer the question, and set 1 for all answer characteristic 12 variables for the learners who provided a perfect answer.

\section{Answer Characteristics for Each Question in the Mid-term Examination}

Here, the variables that represent the answer characteristics extracted from Problem 1-(1) (independence and dependence) in the mid-term exam are shown. The model answer for the question and answer characteristics are shown in Figure 4 and Table 3, respectively. 
Table 3. Answer Characteristics In Problem 1-(1) In The Mid-term Examination

\begin{tabular}{cccc}
\hline Variable name & $\begin{array}{c}\text { Corresponding } \\
\text { answer part }\end{array}$ & $\begin{array}{c}\text { The number of } \\
\text { incorrect answer }\end{array}$ & Example of incorrect answer \\
\hline $\begin{array}{c}\text { Understanding of formula for definition of } \\
\text { independence }\end{array}$ & $\{1\}$ & 12 & $\mathrm{P}(\mathrm{X}, \mathrm{Y})=\mathrm{P}(\mathrm{X})+\mathrm{P}(\mathrm{Y})$ \\
\hline Understanding of definition of probability & $\{3\}\{5\}$ & 14 & $\mathrm{P}(\mathrm{X}=1, \mathrm{Y}=1)=0.050^{2}$ \\
\hline Accurate reading distribution table & $\{3\}\{5\}$ & 10 & $\mathrm{P}(\mathrm{X}=1)=0.050$ \\
\hline Correct numerical calculation & $\{3\}\{5\}$ & 10 & $\mathrm{P}(\mathrm{X}=1) \mathrm{P}(\mathrm{Y}=1)=0.33$ \\
\hline Accurate notation & $\{1\}\{2\}\{4\}$ & 20 & $\mathrm{P}(\mathrm{X} \times \mathrm{Y})=\mathrm{P}(\mathrm{X}) \mathrm{P}(\mathrm{Y})($ Corresponds to $\{1\})$ \\
\hline Clearly stated reason of judgment & $\{6\}$ & 53 & (No statement for reason) \\
\hline
\end{tabular}

Since the population distribution can be expressed as $P\left(X=x_{i}\right)=f\left(x_{i} ; \lambda\right)=\frac{\lambda^{x_{i}} e^{-\lambda}}{x_{i} !}\left(x_{i}=0,1,2, \ldots\right)$

The likelihood function is expressed as $L(\lambda)=\prod_{i=1}^{n} f\left(x_{i} ; \lambda\right)=\frac{\lambda_{i=1}^{n} x_{i}}{e^{-n \lambda}}$

Therefore,

$$
\begin{aligned}
& \frac{\delta}{\delta \lambda} \log L(\lambda)=0 \\
& \Leftrightarrow \frac{\delta}{\delta \lambda}\left\{\left(\sum_{i=1}^{n} x_{i}\right) \log \lambda-n \lambda-\log \left(\prod_{i=1}^{n} x_{i} !\right)\right\}=\frac{1}{\lambda} \sum_{i=1}^{n} x_{i}-n=0 \\
& \Leftrightarrow \lambda=\frac{1}{n} \sum_{i=1}^{n} x_{i}
\end{aligned}
$$

Thus, the maximum likelihood estimator of $\lambda$ is $\hat{\lambda}=\frac{1}{n} \sum_{i=1}^{n} X_{i}=\bar{X}$

$$
\text { 5odel Answer to Problem 1-(1) in the Final Examination }
$$

Figure 5. Model Answer to Problem 1-(1) in the Final Examination

Table 4. Answer Characteristics in Problem 1-(1) in the Final Examination

\begin{tabular}{cccc}
\hline Variable name & $\begin{array}{c}\text { Corresponding } \\
\text { answer part }\end{array}$ & $\begin{array}{c}\text { The number of } \\
\text { incorrect answer }\end{array}$ & $\begin{array}{c}\text { Example of incorrect } \\
\text { answer }\end{array}$ \\
\hline Understanding of the likelihood definition & $\{1\}$ & 7 & $\mathrm{~L}(\lambda)=\sum_{i=1}^{n} f\left(x_{i} ; \lambda\right)$ \\
\hline Correct formula manipulation & $\{3\}$ & 13 & $1 / \lambda \cdot \mathrm{n}=0$ \\
\hline Accurate notation & $\begin{array}{c}\{1\}\{2\} \\
\{3\}\{4\}\end{array}$ & 55 & $\begin{array}{c}\log \left(\sum_{i=1}^{n} x_{i} !\right) \\
\text { (Corresponds to }\{3\})\end{array}$ \\
\hline Complete description & $\{1\}\{2\}\{3\}\{4\}$ & 11 & No description on $\{3\}$ \\
\hline Aware of object of derivation & $\{4\}$ & 8 & $\hat{\lambda}=\frac{\lambda}{n}$ \\
\hline Understanding derivation rules & $\{2\}$ & 11 & No description on $\{2\}$ \\
\hline
\end{tabular}

\section{Answer Characteristics for Each Problem in the Final Examination}

Here, too, the variables representing the answer characteristics extracted from Problem 1-(1) (maximum likelihood estimator) in the final examination are shown. The model answers for the question and answer characteristics are shown in Figure 5 and Table 4, respectively.

\section{ANALYSIS OF LEARNERS' COMPREHENSION AND EXAMINATION OF LEARNING AND EDUCATION POLICY BASED ON THEIR COMPREHENSION}

This chapter analyzes learners' comprehension for each problem based on the answer characteristics variables extracted in Chapter 3, and proposes and examines a method for promoting qualitative improvement in the learning method and subject comprehension. First, a framework is given for each problem to analyze the relationship between the level of learners' comprehension (scores within the problem) and the qualitative difference (answer characteristics) using regression tree analysis. Then, the relationship between comprehension level, as characterized by the answer characteristic variables for each question and learners' total score, is analyzed using item characteristic chart. 


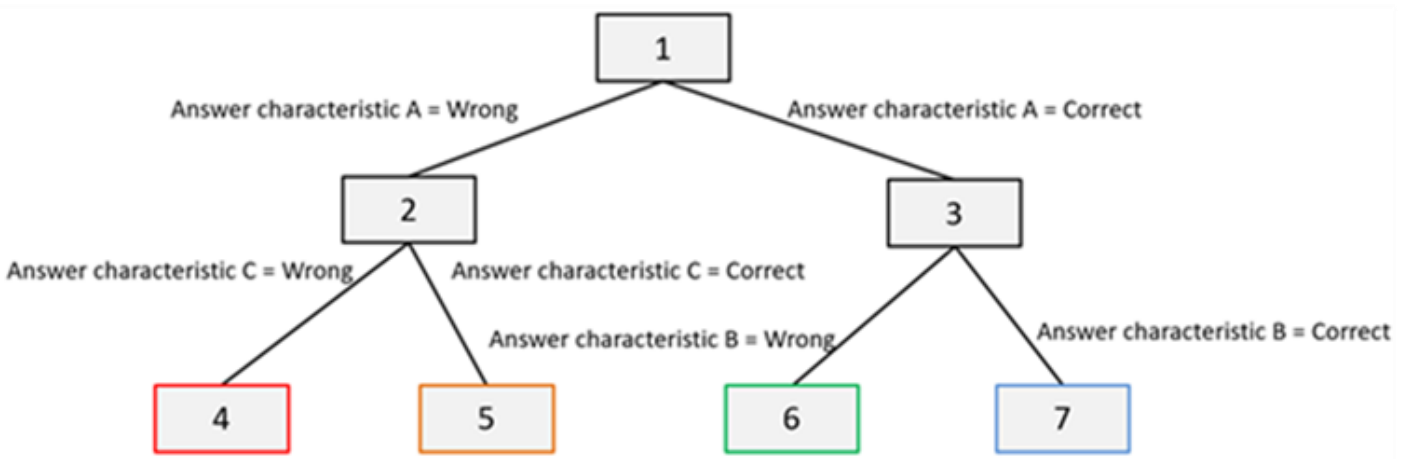

Figure 6. Answer Segmentation Via Regression Tree Analysis

Table 5. Relationship Between Answer Characteristic and Terminal Node

\begin{tabular}{ccccc}
\hline \multirow{2}{*}{ Terminal node } & \multicolumn{4}{c}{ Answer characteristic } \\
\cline { 2 - 5 } & B1 & B2 & B3 & B4 \\
\hline 4 & Wrong & - & Wrong & - \\
\hline 5 & Wrong & - & Correct & - \\
\hline 6 & Correct & Wrong & - & - \\
\hline 7 & Correct & Correct & - & - \\
\hline
\end{tabular}

\section{Segmentation of Learners by Question based on the Answer Characteristics Variables Using Regression Tree and Comprehension Analysis Using Item Characteristic Chart}

In this section, learners will be segmented into groups by question using the answer characteristics variables.

\section{Learner segmentation via regression tree analysis}

Decision tree analysis is a procedure comprising the recursive segmentation and structuring of objects on a tree by conditionalizing the explanatory variables that most eminently characterize the difference in the objective variable. In our study, since the objective variable is an ordinal scale, a regression tree analysis will be performed (Targo, 2017).

$$
S_{T}-\left(S_{L}+S_{R}\right) \rightarrow \max
$$

Note that $\mathrm{S}_{\mathrm{T}}$ represents the sum of the squared deviation of the objective variable, $\mathrm{S}_{\mathrm{L}}$ is the sum of the squared deviation of the objective variable in a left node after segmentation, and $\mathrm{S}_{\mathrm{R}}$ is the sum of the squared deviation of the objective variable in the right node.

The segmentation of learners in the regression tree is explained below. In a tested problem from which four answer characteristics-B1, B2, B3, and B4-were obtained, learners are classified into four terminal nodes (nodes 4, 5, 6, and 7), as shown in Figure 6.

The score of the problem is provided as the objective variable, and the answer characteristics are provided as the explanatory variable. Answers with different characteristics are allocated to four terminal nodes according to the branching rule of the regression tree. At this point, note that the correctness cannot be uniformly determined for answer characteristics B2 and B4 in terminal nodes 4 and 5, or for answer characteristics B3 and B4 in terminal nodes 6 and 7. These answer characteristics are not represented on the tree structure; they may either be the parts of the answer that constitute smaller proportions of the total score or possess extreme difference between the number of correct answers and the number of incorrect answers of learners in the answer characteristics. Therefore, the distribution of explanatory variables must be understood when examining the results of the regression trees.

One goal of the classification of answers using a regression tree is to categorize the answers themselves based on quantitative (points) and qualitative information (answer characteristics) and to extract problems that arise in the learning or educational methods. Educators are able to gain qualitative information that reveals "what kind of mistake is found in common" via the explanatory variables reflected in the regression tree as routes from the root to the terminal nodes, along with quantitative information, such as the mean score within a terminal node and the number of answers classified. 


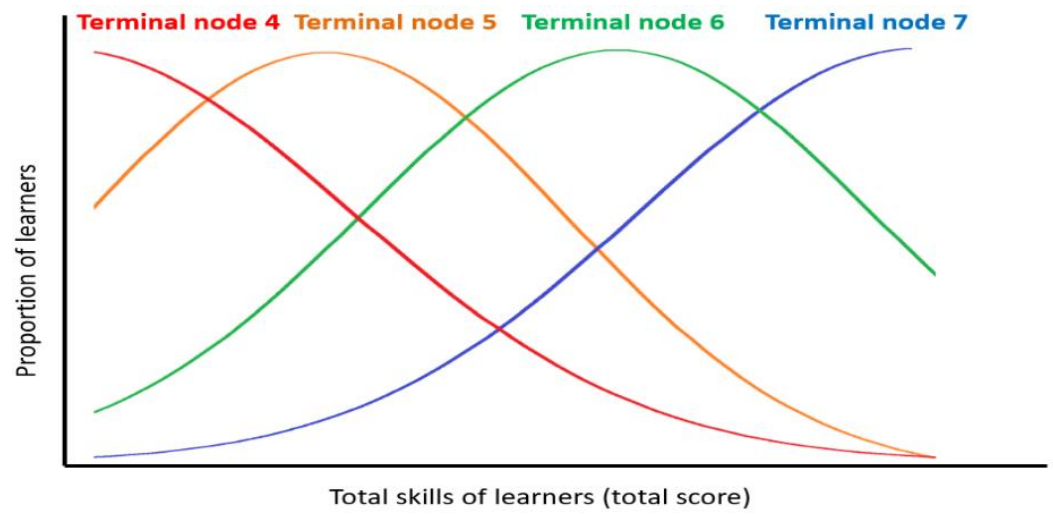

Figure 7. Association Between the Transition of Terminal Nodes and the Total Score of Learners

Further, the structure of the regression tree can be interpreted to express a transition in the learners' comprehension levels. In the example illustrated in Figure 6, the mastery of study content expressed in answer characteristic B3 best explains the difference in the levels of comprehension between terminal node 4 and 5; a learner at terminal node 4 can improve his or her comprehension such that it reaches the level represented in terminal node 5 by learning the study content of answer characteristic B3. Likewise, a learner at terminal node 6 can improve his or her comprehension to reach the level expressed in terminal node 7 by learning the study content expressed by answer characteristic B2. Therefore, a learner at terminal node 4 can effectively improve his or her comprehension by understanding answer characteristic B3, which characterizes the difference between terminal nodes 4 and 5 ; a learner at terminal node 5 can accomplish this as well by understanding answer characteristic B1, which characterizes the difference between terminal nodes 5 and 6 , and a learner at terminal node 6 can accomplish this as well by learning answer B2, which characterizes the difference between terminal nodes 6 and 7 . Thus, the answer characteristics that characterize the terminal nodes can be understood as study policies that indicate what learners at each stage should do next to improve their understanding.

Further, a positive association between the transition of the answer characteristic at terminal nodes and the total abilities (total score) of the learner is predicted. For example, a learner with a higher total score is predicted to have a greater probability of arriving at the stage of comprehension represented by terminal node 7, rather than terminal node 4 in a problem like that illustrated in Figure 6. The association between the transition of the answer characteristic at terminal nodes and total abilities in the case of Figure 6 as an example is shown in Figure 7.

A learner's total comprehension can be grasped by inspecting whether the proportions of learners at each terminal node have the distribution shapes illustrated in Figure 7. One technique for visualizing the relationship between learners' understanding for each problem and the total score, as shown in Figure 7, is an analysis via an item characteristic chart used in the item analysis for multiple-choice questions. Thus, this study tries to understand the total comprehension of learners for each error type (segment) by applying an item characteristic chart.

\section{Error analysis via item characteristic chart}

The significance of considering an item characteristic chart for the analysis of error trends in multiplechoice questions has been demonstrated by Akiyama, Toyota and Iwama (2015). Akiyama, Toyota, and Iwata (2015) state that creating item characteristic curves results in parts that examinees tend to get wrong when their answers are classified into several categories. Since it is difficult to straightforwardly apply an analysis from an item characteristic chart to answers for a test with full descriptive-type questions, such an analysis has not been performed. However, in this study, by understanding the segments (terminal nodes) classified using regression trees as choices in multiple-choice questions, an analysis from the item characteristic chart will be applied to full descriptive questions.

An item characteristic chart can be created by dividing test examinees into approximately 5 groups ordered based on the total test score, with each comprising an approximately equal number of members. The selection rate for each answer category within a group along the vertical axis for the groups along the horizontal axis is plotted; the plotted choices of all groups are then connected with a straight line. For example, consider a multiple-choice question with 4 choices, A, B, C, and D, as explained in the item characteristic chart (Figure 


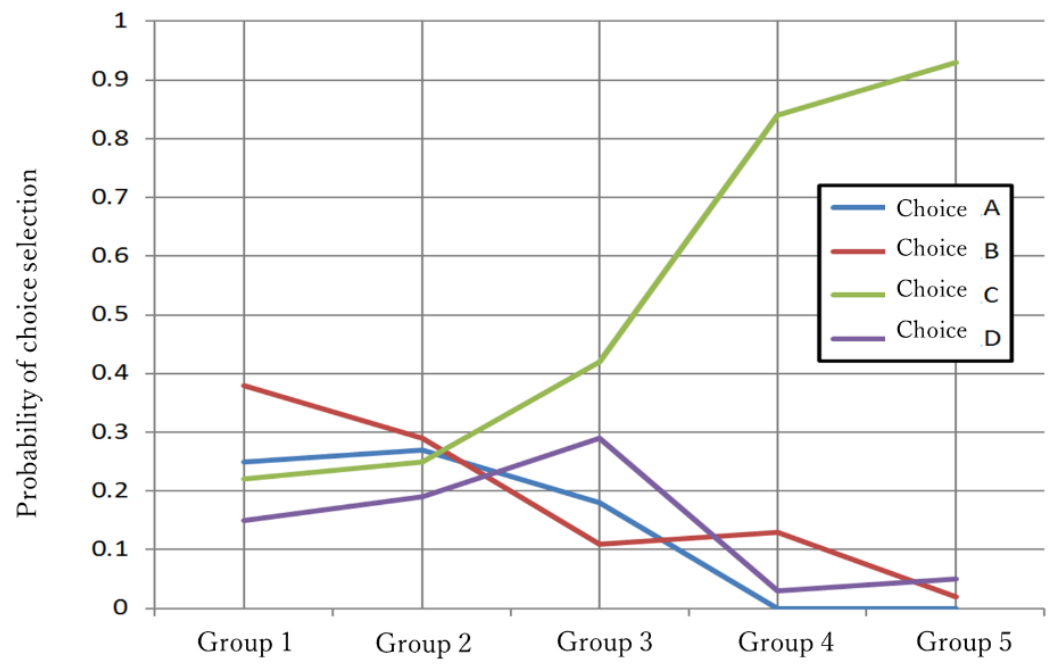

Figure 8. Item Characteristic Chart In 4-multiple-choice Question (Example)

8). Suppose the correct answer is choice C. The examinees were divided into five groups in ascending order according to the total test score.

The curve that represents the selection rate of the correct answer is termed the correct response curve, and curves that represent the selection rates of wrong answers are termed wrong response curves. An analysis of the correct response curve allows us to measure the intent of the test creators as well as the adequacy of problems, by considering the position at which the correct response curve starts to become steep curve, as well as the slope. Since the correct response curve in Figure 8 forms a steep curve between groups 3 and 4 , it is thought to be particularly instrumental choice in discriminating the difference in abilities between groups 3 and 4. Regarding the wrong response curves, it is important to interpret why the wrong answers that are selected at high probabilities are indeed selected by the concerned group, based on the content of the wrong answer.

\section{Segmentation by Problem of Learners in the Mid-term Examination and their Comprehension Analysis}

Results of analyses of learners' levels of comprehension based on the answer characteristic variables in Problem 1-(1) (independence, dependence) are shown as an example.

From Figure 9 (1), learners were classified into 6 terminal nodes. Out of 89 learners (node 1), 75 (node 3) were able to answer correctly regarding the "understanding of probability definition," which represents the comprehension of definitions for concepts such as joint probability. Out of 75 leaners(node3), which 72 learners (node 7) answered correctly for the "understanding of formula for the definition of independence," which tests the comprehension of the concept of independence. Additionally, of the 72 learners who provided correct answers according to two answer characteristics: "understanding of probability definition" and "understanding of formula for the definition of independence," 27 learners (node 15) responded correctly for the "Clearly stated reason of judgment," which asks examinees to properly describe the reason for evaluating the case in the question as independent. At nodes 14 and 15, 39 (node 29) and 24 participants (node 31), respectively, provided a correct response for the "Accurate notation," which is designed to test the knowledge of symbols for concepts such as joint probability.

As shown in Figure 9 (2), the distribution of learners for each group at each terminal node reveals that group 4 accounts for the highest proportion of learners at terminal node 31 , who are considered to have understood the problem better than everyone else; the number declines with group 5 . This means that the correct response rate for the "Clearly stated for reason of judgment" is reversed between the high score groups, groups 4 and 5, and is a type of errors that high-scoring learners in group 5 tend to get wrong, compared to those in group 4. Further, the proportion of learners who fail to demonstrate their grasp of "understanding of probability definition," an answer characteristic at terminal node 2, reveals a sharp decline from groups 1 to 2; no group 2 members exist in node 2, while some members from groups 3 to 5 are included. These learners 


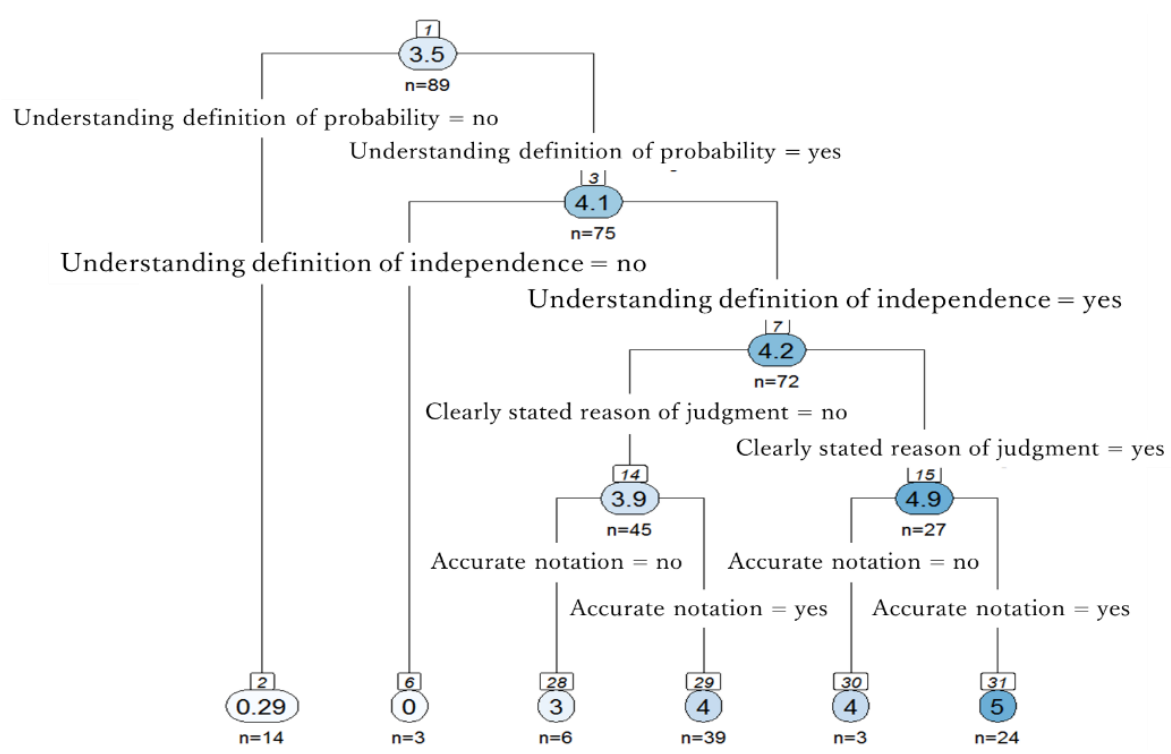

(1) Segmentation of Learners

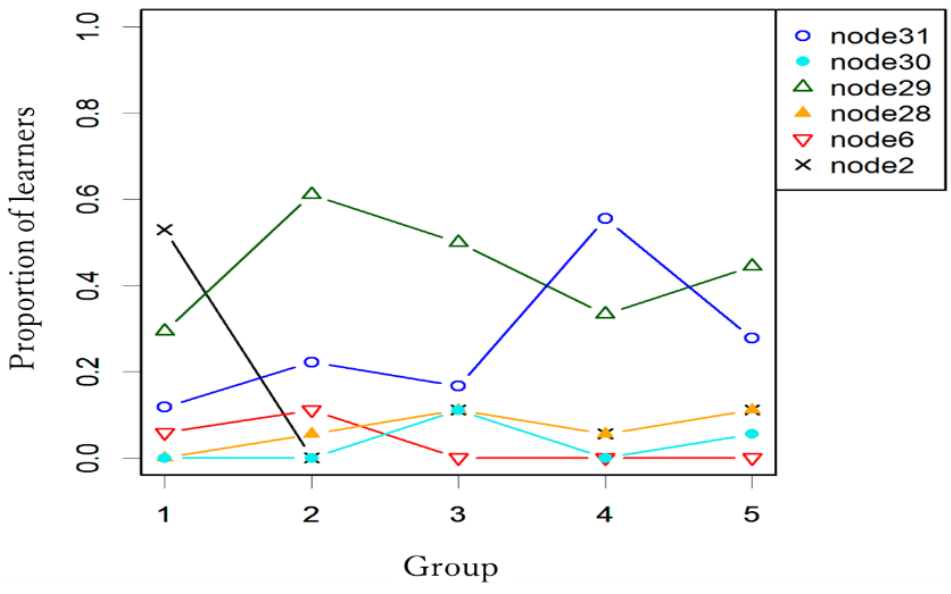

(2) Item Characteristic Chart

Figure 9. Segmentation of Learners in Problem 1-(1) in the Mid-term Examination and Item Characteristic Chart

Table 6. Expressions of Terminal Nodes through Answer Characteristic Variables in Problem 1-(1) in the Mid-term Exam

\begin{tabular}{cccccc}
$\begin{array}{c}\text { Terminal The number } \\
\text { node } \\
\text { of people }\end{array}$ & \multicolumn{5}{c}{ Answer characteristic variable } \\
\hline \multicolumn{7}{c}{$\begin{array}{c}\text { Understanding } \\
\text { definition of probability }\end{array}$} & $\begin{array}{c}\text { Understanding formula for } \\
\text { definition of independence }\end{array}$ & $\begin{array}{c}\text { Clearly stated } \\
\text { reason of judgment }\end{array}$ & $\begin{array}{c}\text { Accurate } \\
\text { notation }\end{array}$ \\
\hline 2 & 14 & $\times$ & & & \\
\hline 6 & 3 & 0 & $\times$ & $\times$ & $\times$ \\
\hline 28 & 6 & 0 & 0 & $\times$ & 0 \\
\hline 29 & 39 & 0 & 0 & 0 & $\times$ \\
\hline 30 & 3 & 0 & 0 & 0 & 0 \\
\hline 31 & 24 & 0 & 0 & & \\
\hline
\end{tabular}

may not have properly understood the definition of probability and even if they achieved higher scores, an improvement in their understanding is desired. 


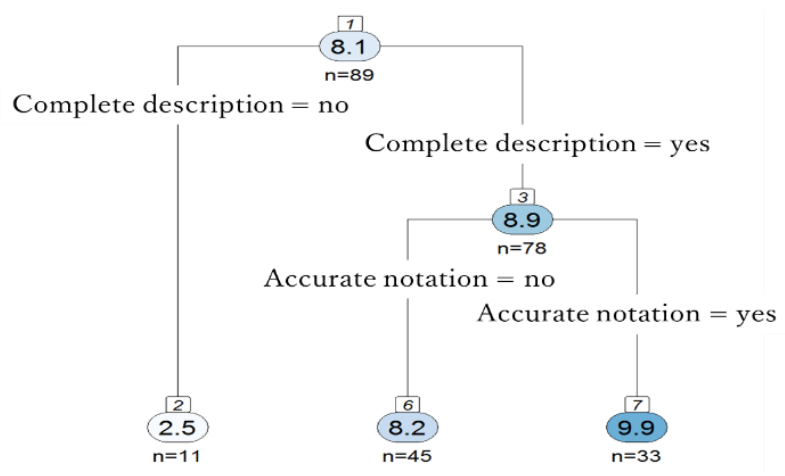

(1) Learner segmentation

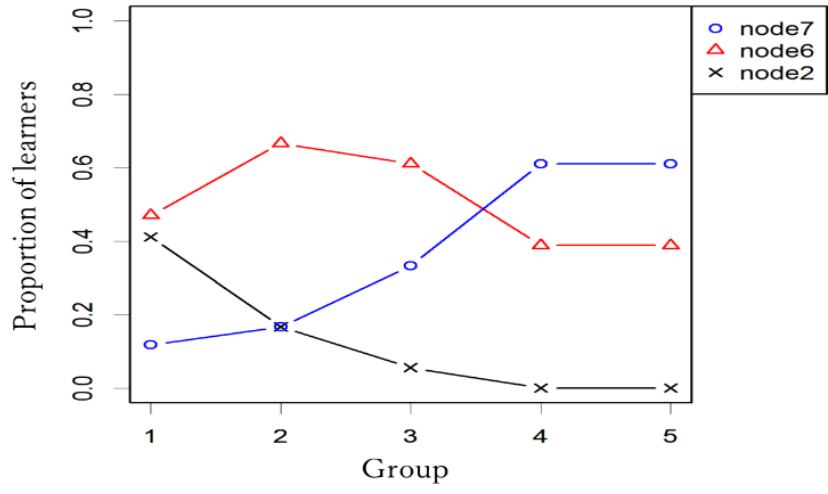

(2) Item characteristic chart

Figure 10. Segmentation of Learners in the Problem 1-(1) in the Final Exam and Item Characteristic Chart

Table 7. Expressions of Terminal Nodes through Answer Characteristic Variables in Problem 1-(1) of the Final Exam

\begin{tabular}{cccc}
\hline \multirow{2}{*}{ Terminal node } & \multirow{2}{*}{ The number of people } & \multicolumn{2}{c}{ Explanatory variable } \\
\cline { 3 - 4 } & 11 & Complete description & Accurate notation \\
\hline 2 & 45 & $\times$ & $\times$ \\
\hline 6 & 33 & $\circ$ & $\circ$ \\
\hline 7 & & $\circ$ & \\
\hline
\end{tabular}

\section{Segmentation by Problem of Learners in the Final Examination and their Comprehension Analysis}

Results of the analysis of learners' comprehension based on the answer characteristic variables in Problem 1-(1) (maximum likelihood estimate) are shown below for illustration purposes.

As shown in Figure 10 (1), the learners were divided into three terminal nodes. The answer characteristic that divides the entire group of 89 participants (Node 1) is "Complete description;" of the 78 learners who correctly answered this question (Node 3), 33 were also able to answer "accurate notation" correctly, as represented in terminal node 7 .

To examine the proportion of members in each group in the terminal nodes shown in the item characteristic chart (Figure 10(2)), groups 4 and 5 are found to have higher proportions of learners who correctly responded to both "Complete description" and "Accurate notation" (Node 7). Further, the proportion of learners in terminal node 2 (who meet neither "Complete description" nor "Correctness of description") declines in the order of groups 1 to 4 , and groups 4 and 5 are 0 . Of all the learners, the proportion of learners who answered correctly for "Complete description" and incorrectly for "Accurate notation" (Node 6) was relatively high for all groups; 45 learners fall under this terminal node 6, with particularly high numbers from groups 2 and 3. 
Table 8. Learning Policy According To Learners' Levels Of Comprehension Of Each Problem (1) Mid-term examination

\begin{tabular}{|c|c|c|c|c|}
\hline \multirow{2}{*}{ Problems } & \multirow{2}{*}{$\begin{array}{c}\text { Terminal } \\
\text { node }\end{array}$} & \multicolumn{3}{|c|}{ Learning policy } \\
\hline & & $\begin{array}{l}\text { Learning policy } 1 \\
\end{array}$ & Learning policy 2 & Learning policy 3 \\
\hline \multirow{5}{*}{$1-(1)$} & 2 & Understanding definition of probability & & \\
\hline & 6 & $\begin{array}{l}\text { Understanding if formula for definition of } \\
\text { independence }\end{array}$ & & \\
\hline & 28 & Accurate notation & Clearly stated reason of judgment & \\
\hline & 29 & Clearly stated reason of judgment & & \\
\hline & 30 & Accurate notation & & \\
\hline \multirow{3}{*}{$1-(2)$} & 2 & $\begin{array}{c}\text { Understanding definition of conditional } \\
\text { probability }\end{array}$ & & \\
\hline & 6 & $\begin{array}{l}\text { Understanding definition of conditional } \\
\text { expectation }\end{array}$ & & \\
\hline & 14 & Accurate notation & & \\
\hline \multirow[t]{2}{*}{$1-(3)$} & 2 & $\begin{array}{c}\text { Understanding definition of expected values } \\
\text { for two variables } \\
\end{array}$ & & \\
\hline & 6 & Correct numerical calculation & & \\
\hline \multirow{3}{*}{$1-(4)$} & 4 & $\begin{array}{l}\text { Understanding definition of expected value of } \\
\text { a single variable }\end{array}$ & $\begin{array}{l}\text { Understanding definition of } \\
\text { variance of a single variable }\end{array}$ & \\
\hline & 5 & $\begin{array}{c}\text { Understanding definition of variance of a } \\
\text { single variable }\end{array}$ & & \\
\hline & 6 & Correct numerical calculation & & \\
\hline 2 & 2 & Accurate reading of conditional probability & & \\
\hline \multirow{3}{*}{$3-(1)-1$} & 4 & Aware of object of proof & $\begin{array}{l}\text { Understanding the property of } \\
\text { continuous distribution }\end{array}$ & \\
\hline & 5 & $\begin{array}{c}\text { Understanding the property of continuous } \\
\text { distribution }\end{array}$ & & \\
\hline & 6 & Complete description & & \\
\hline \multirow{6}{*}{$3-(1)-2$} & 8 & Understanding definition of variance & Aware of object of proof & $\begin{array}{c}\text { Understanding the } \\
\text { property of continuous } \\
\text { distribution }\end{array}$ \\
\hline & 9 & Aware of object of proof & $\begin{array}{l}\text { Understanding the property of } \\
\text { continuous distribution }\end{array}$ & \\
\hline & 5 & $\begin{array}{l}\text { Understanding the property of continuous } \\
\text { distribution }\end{array}$ & & \\
\hline & 12 & Aware of object of proof & Complete description & \\
\hline & 13 & Complete description & & \\
\hline & 14 & Understanding calculation rules & & \\
\hline $3-(1)-3$ & 2 & $\begin{array}{l}\text { Understanding definition of distribution } \\
\text { function }\end{array}$ & & \\
\hline \multirow{3}{*}{$3-(2)$} & 4 & Complete description & Correct numerical calculation & \\
\hline & 10 & Understanding standardization & Correct numerical calculation & \\
\hline & 11 & Correct numerical calculation & & \\
\hline \multirow{5}{*}{$4-(1)$} & 8 & Understanding Constraint 2 & $\begin{array}{l}\text { Correct distribution formula } \\
\text { manipulation }\end{array}$ & $\begin{array}{l}\text { Understanding limit } \\
\text { calculation }\end{array}$ \\
\hline & 9 & Correct distribution formula manipulation & Understanding limit calculation & \\
\hline & 10 & Understanding Constraint 1 & Understanding limit calculation & \\
\hline & 11 & Understanding limit calculation & & \\
\hline & 6 & Complete description & & \\
\hline \multirow{4}{*}{$4-(2-1)$} & 2 & $\begin{array}{l}\text { Understanding definition of probability } \\
\text { function }\end{array}$ & & \\
\hline & 6 & Accurate reading of distributed information & & \\
\hline & 14 & Accurate notation & & \\
\hline & 30 & Understanding distribution parameters & & \\
\hline \multirow{3}{*}{$4-(2-2)$} & 2 & Correct numerical calculation of second term & & \\
\hline & 12 & Correct numerical calculation of first term & $\begin{array}{c}\text { Understanding definition of } \\
\text { discrete distribution probability }\end{array}$ & \\
\hline & 13 & $\begin{array}{l}\text { Understanding definition of discrete } \\
\text { distribution probability }\end{array}$ & & \\
\hline
\end{tabular}

\section{Learning Policy According to Learners' Level of Comprehension of Each Problem}

A summary of the answer characteristics for each problem in the mid-term and final examinations that characterizes the terminal nodes drawn from the regression tree analysis is shown in Table 8 as the learning policies for learners at each terminal node. 
Tsubaki et al.

Table 8 (continued). Learning Policy According To Learners' Levels Of Comprehension Of Each Problem

(2) Final examination

\begin{tabular}{|c|c|c|c|}
\hline \multirow{2}{*}{ Problem } & \multirow{2}{*}{$\begin{array}{c}\text { Terminal } \\
\text { node }\end{array}$} & \multicolumn{2}{|c|}{ Learning policy } \\
\hline & & Learning policy 1 & Learning policy 2 \\
\hline \multirow{2}{*}{$1-(1)$} & 2 & Complete description & \\
\hline & 6 & Accurate notation & \\
\hline \multirow{4}{*}{$1-(2-1)$} & 4 & Understanding definition of unbiasedness & Complete description \\
\hline & 5 & Complete description & \\
\hline & 6 & Understanding definition of expected value & \\
\hline & 14 & Accurate notation & \\
\hline \multirow{6}{*}{$1-(2-2)$} & 8 & Aware of object of proof & $\begin{array}{l}\text { Correct formula } \\
\text { manipulation }\end{array}$ \\
\hline & 9 & Accurate notation & Correct formula manipulation \\
\hline & 10 & Complete description & Correct formula manipulation \\
\hline & 11 & Correct formula manipulation & \\
\hline & 6 & Aware of object of proof & \\
\hline & 14 & Complete description & \\
\hline \multirow{5}{*}{$1-(2-3)$} & 4 & Accurate notation & Correct formula manipulation \\
\hline & 5 & Correct formula manipulation & \\
\hline & 12 & Understanding Chebyshev's inequality & Complete description \\
\hline & 13 & Complete description & \\
\hline & 14 & Accurate notation & \\
\hline \multirow{6}{*}{$2-(1)$} & 4 & Understanding definition of errors in two-sided test & $\begin{array}{l}\text { Understanding definition of power in } \\
\text { two-sided test }\end{array}$ \\
\hline & 10 & Understanding situations where power is increased & $\begin{array}{l}\text { Understanding definition of power in } \\
\text { two-sided test }\end{array}$ \\
\hline & 11 & Understanding definition of power in two-sided test & \\
\hline & 12 & Correct graphical demonstration of errors in test & $\begin{array}{l}\text { Understanding situations where } \\
\text { power is increased }\end{array}$ \\
\hline & 13 & Understanding situations where power is increased & \\
\hline & 14 & Correct graphical demonstration of errors in test & \\
\hline \multirow{6}{*}{$2-(2)$} & 8 & Correct graphical demonstration of errors in test & $\begin{array}{c}\begin{array}{c}\text { Understanding definition of power in Understanding definition of } \\
\text { one-sided test }\end{array} \\
\text { errors of one-sided test }\end{array}$ \\
\hline & 9 & Understanding definition of power in one-sided test & $\begin{array}{l}\text { Understanding definition of power in } \\
\text { one-sided test }\end{array}$ \\
\hline & 5 & Understanding definition of power in one-sided test & \\
\hline & 12 & Correct graphical demonstration of errors in test & $\begin{array}{c}\text { Understanding difference between } \\
\text { power in two-sided test and power in } \\
\text { one-sided test }\end{array}$ \\
\hline & 13 & $\begin{array}{l}\text { Understanding difference between power in two-sided test } \\
\text { and power in one-sided test }\end{array}$ & \\
\hline & 14 & Correct graphical demonstration of errors in test & \\
\hline \multirow{3}{*}{$3-(1)$} & 4 & Aware of object of derivation & $\begin{array}{l}\text { Description of distribution that the } \\
\text { statistics follows }\end{array}$ \\
\hline & 5 & Description of distribution that the statistics follows & \\
\hline & 6 & Understanding derivation rules & \\
\hline \multirow{4}{*}{$3-(2)$} & 4 & Understanding definition of unbiased variance & $\begin{array}{l}\text { Accurate reading of percentage } \\
\text { points in chi-square distribution }\end{array}$ \\
\hline & 5 & $\begin{array}{l}\text { Accurate reading of percentage points in chi-square } \\
\text { distribution }\end{array}$ & \\
\hline & 6 & Understanding definition of confidence interval & \\
\hline & 14 & Correct numerical calculation & \\
\hline \multirow{3}{*}{$3-(3)$} & 2 & Understanding definition of confidence interval & \\
\hline & 6 & Accurate reading of percentage points in t-distribution & \\
\hline & 14 & Correct numerical calculation & \\
\hline \multirow{6}{*}{$4-(1)$} & 8 & Clearly stated test hypothesis & $\begin{array}{l}\text { Understanding definition of } \\
\text { confidence interval }\end{array}$ \\
\hline & 9 & Understanding definition of confidence interval & $\begin{array}{l}\text { Understanding definition of test } \\
\text { statistic }\end{array}$ \\
\hline & 10 & Clearly stated test hypothesis & $\begin{array}{l}\text { Understanding definition of test } \\
\text { statistic }\end{array}$ \\
\hline & 11 & Understanding definition of test statistic & \\
\hline & 6 & Clearly stated test hypothesis & \\
\hline & 14 & $\begin{array}{l}\text { Understanding how to calculate percentage points in } \mathrm{F} \\
\text { distribution }\end{array}$ & \\
\hline \multirow{6}{*}{$4-(2)$} & 8 & Understanding definition of pooled unbiased variance & $\begin{array}{l}\text { Accurate reading of percentage } \\
\text { points in t-distribution }\end{array}$ \\
\hline & 9 & Accurate reading of percentage points in t-distribution & $\begin{array}{l}\text { Understanding definition of test } \\
\text { statistic }\end{array}$ \\
\hline & 5 & Understanding definition of test statistic & \\
\hline & 12 & Accurate reading of percentage points in t-distribution & Correct numerical calculation \\
\hline & 13 & Correct numerical calculation & \\
\hline & 14 & Accurate reading of percentage points in t-distribution & \\
\hline
\end{tabular}




\section{ANALYSIS OF THE RELATIONSHIP BETWEEN LEARNING POLICY AND ANSWER CHARACTERISTICS FOP QUALITATIVE IMPROVEMENT IN LEARNERS' LEARNING OF PROBABILITY AND STATISTICS}

In this chapter, the relationship between the answer characteristics and the learning policy obtained from the questionnaire survey will be analyzed using Bayesian networks to individually derive the learning policies that are useful in improving errors made by learners. Chen, Feng, Hu and Sun (2019) is to construct a Bayesian network to make causal analysis and then provide personalized interventions for different learners to improve learning. However, they do not model the relationship between the questionnaire survey and the test answer characteristics based on error analysis.

\section{Binarization of Learning Strategies based on Questionnaire Survey Results}

As shown in Table 1 in Chapter 2, the questionnaire survey administered in this study consists of 29 items (16+6+7 items) comprising 5-point scale questions (16 items), numerical input questions (6 items), and the selective question with 7 choices that allow multiple answers is considered as 7 yes-or-no questions. Amongst the latter type of question, all respondents chose No (0: No) for the questions "Video material" and "Others," which represent the materials used. Thus, they were excluded and the remaining 27 items were designated as the variables for the learning strategies.

In this chapter, the learning strategy variables will be binarized to analyze the relationship between the learning strategies and the answer characteristics using Bayesian network models. Regarding 16 questions evaluated on a 5-point scale in Table 1, 3 negative answers to the question, 1: Strongly disagree, 2: Disagree, and 3: Undecided, were regarded as 0, and 2 positive answers, 4: Agree, 5: Strongly agree, were regarded as 1. Regarding 6 questions of the numerical input type in Table 1, the mean value is understood as a point of reference, since values less than the mean were regarded as 0 , and the mean value and those greater than the mean were regarded as 1 .

\section{Extraction of Learning Strategies Using Probabilistic Reasoning through Bayesian Network Models}

This study proposes a method to quantitatively detect and evaluate learning strategies that are instrumental in eliminating mistakes and qualitatively improving learning by building a Bayesian network model that relates answer characteristics to the learning strategy and answer characteristics for each question and makes a probabilistic reasoning for each individual learner.

Regarding the Bayesian networks, refer to Scutari and Denis (2014), Lqbal, Yin, Hao, IIyas and Ali (2015). In the Bayesian network model $\mathrm{M}$, consider the learning strategy $X$, which is in direct probabilistic relation to characteristic $Y$, as the learning strategy that can be deemed useful for learners as a whole by evaluating whether the value of $\mathrm{D}$ in the following formula is positive or negative, in addition to its quantity.

$$
D=P(Y=1 \mid X=1, M)-P(Y=1 \mid X=0, M)
$$

The use of the learning strategy $X$, which causes the value of $\mathrm{D}$ in formula (7) to be positive, is considered to promote understanding of the learned content, as represented in the answer characteristic $Y$, as well as the required improvement in associated skills. Moreover, if there is more than one learning strategy $X$ for a single answer characteristic $Y$, which causes the solution of formula (7) to be positive, the learning strategy $X$, which maximizes the value of $\mathrm{D}$ in formula (7), is deemed most effective.

\section{Extraction of Learning Strategies for Qualitative Improvement in Learning for Learners in the Mid-term Exam}

In the structural search for Bayesian network models, an AIC-based Greedy Search algorithm included in the "bnlearn" R package was adopted. Here, to obtain a better model while preventing local optimization, the structural search for Bayesian network models was repeated 1000 times while randomly changing the initial values, and a model minimizing the AIC was adopted.

Let us explain the constraints imposed on the model structure of the Bayesian network model in the midterm examination. First, it is reasonable to assume that the comprehension of the learned content, as well as the mastery of associated skills as represented by the answer characteristic variables, is a consequence of learning using the strategies represented by the learning strategy variables. It is therefore inappropriate to 


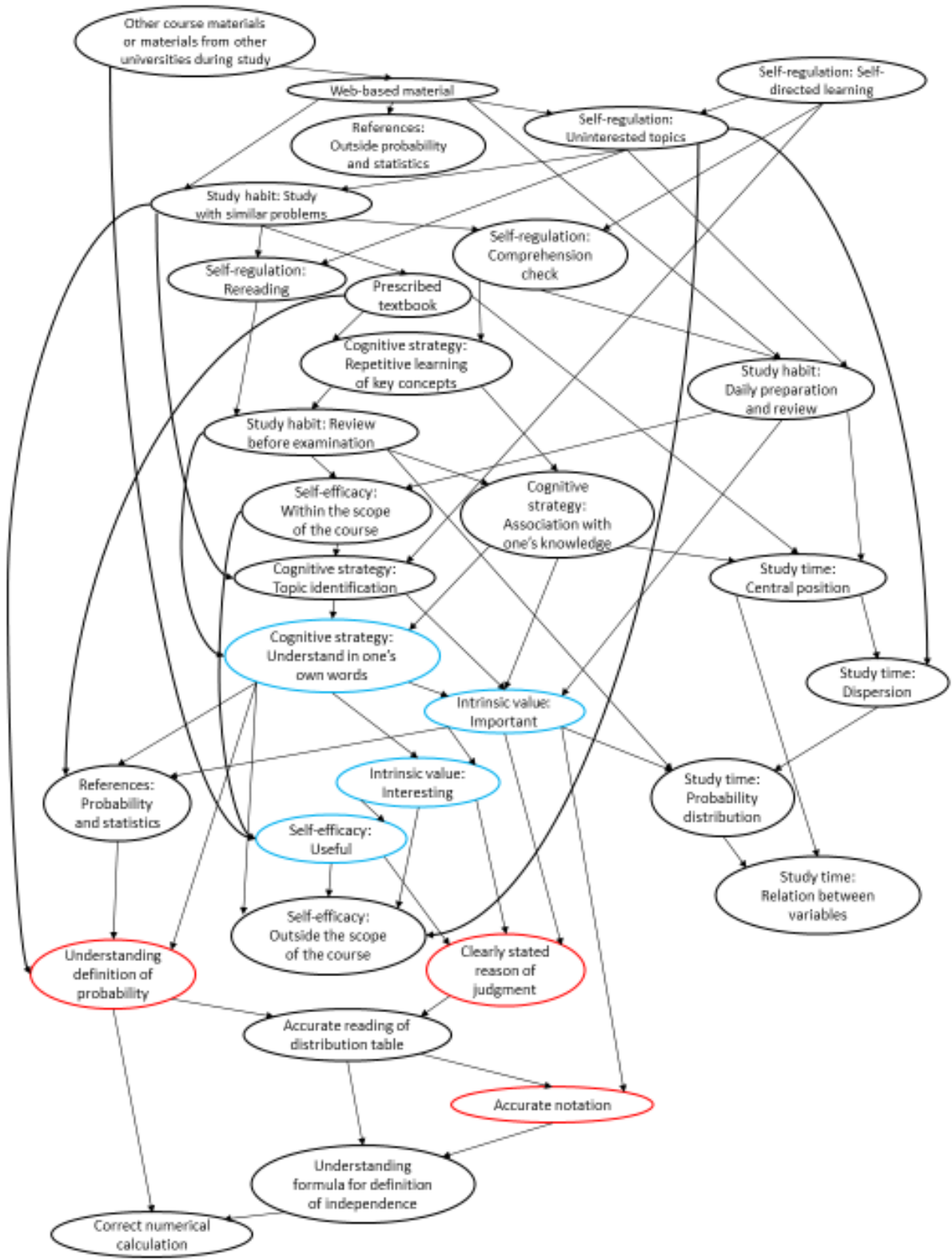

Figure 11. Structuration Of A Bayesian Network For The Answer Characteristics And Learning Strategies Of Problem 1-(1)

use the type of models with an edge structure in which the answer characteristic variable occupies the parent node and the learning strategy variable occupies the child node; hence, a constraint is imposed on all answer characteristic variables by disallowing them from possessing learning strategy variables as their child nodes. Regarding the two learning strategy variables, "Study time: Statistical estimation" and "Study time: Statistical testing," both of which represent the hours of study spent on topics tested in the final examination, it is appropriate to conclude that they do not affect learners' mid-term examination results. Thus, of all 27 parameters that express learning strategies, two variables, "Study time: Statistical estimation," and "Study time: Statistical testing", were excluded, which reduced the number of learning strategy variables to 25.

In the figure of the Bayesian network model below, the nodes in the blue and red boxes are learning strategy variables and answer characteristic variables, respectively, which were observed to have a direct positive probabilistic dependent relationship.

Here, the results of extracting the learning strategies to improve the answer characteristics in Problem 1(1) (independence, dependence) are shown as an example. 
Table 9. Conditional Probabilities At The Edges That Were Observed To Have Direct, Positive Probabilistic Dependent Relationships With The Answer Characteristic Variables

\begin{tabular}{ccc}
\hline $\begin{array}{c}\text { Learnitive strategy: Understand } \\
\text { in one's own words }\end{array}$ & Answer characteristic variable $\mathbf{Y}$ & $\mathbf{D}=\mathbf{P}(\mathbf{Y}=\mathbf{1} \mid \mathbf{X}=\mathbf{1}, \mathbf{M})-\mathbf{P}(\mathbf{Y}=\mathbf{1} \mid \mathbf{X}=\mathbf{0}, \mathbf{M})$ \\
\hline Intrinsic value: Important & Accurate notation & 0.125 \\
\hline Intrinsic value: Important & Clearly stated reason of judgment & 0.169 \\
\hline Intrinsic value: Interesting & Clearly stated reason of judgment & 0.078 \\
\hline Self-efficacy: Useful & Clearly stated reason of judgment & 0.178 \\
\hline
\end{tabular}

Of all pairs of nodes observed to have a direct, probabilistic dependent relationship from the learning strategy variable to the answer characteristic variable, those with a positive relationship are shown in Table 9. For "Understanding of probability definition," which expresses the most basic understanding of this Problem, "Cognitive strategy: Understand in one's own words," i.e., a strategy of studying basic concepts in one's own words, is suggested as effective $(\mathrm{D}=0.125)$. An awareness of the significance of learning probability and statistics as expressed by "Intrinsic value: Important" is considered to affect the understanding of "Accurate notation" and "Clearly stated reason of judgment" $(\mathrm{D}=0.169, \mathrm{D}=0.078)$. Furthermore, "Clearly stated for reason of judgment" is most probabilistically affected by "Self-efficacy: Useful" ( $D=0.477)$, delineating the importance of an actual awareness of the usefulness of probability and statistics.

As for problems in the mid-term examination, of all pairs of nodes observed to have a direct, probabilistic dependent relationship from the learning strategy variable to the answer characteristic variable, those with a positive relationship are summarized in Table $\mathbf{1 0}$ to examine the relationships between the learning strategies and answer characteristics.

Regarding the learning strategy "Self-efficacy," "Self-efficacy: Useful" was revealed as effective for "Clearly stated reason of judgment" in Problem 1-(1) and "Correct numerical calculation" in Problems 1-(2) and 2. These answer characteristics can be answered correctly through an understanding of basic learning content for problems which mainly deal with relationships between probabilistic parameters. Hence, these relationships suggest the importance of having self confidence that, for further improvement on the understanding of fundamental concepts learned regarding the relationship between the probabilistic variables, probability and statistics can be properly applied to the actual states of affairs. Meanwhile, "Self-efficacy: Within the scope of the course" and "Self-efficacy: Outside the scope of the course" are the learning strategies considered effective for answer characteristics regarding the properties of the probability distribution, including "Aware object of proof" in Problem 3-(1)-1, which mainly deals with probability distribution, "Understanding properties of continuous distribution" in Problem 3-(1)-2, and "Understanding properties of normal distribution" in Problem 3-(1)-3.

As for the learning strategy "Intrinsic value," "Intrinsic value: Important" was suggested as an effective learning strategy for "Accurate notation" and "Clearly stated reason of judgment" in Problem 1-(1), which mainly deals with relationships between probability variables, as well as for "Properties of continuous distribution" in Problem 3-(1)-1, which deals with probability distribution, and "Aware object of proof" in Problem 3-(1)-2; meanwhile, "Intrinsic value: Interesting" was revealed as effective for Problems 1-(1) and 1(2), which mainly deal with relationships between probability variables.

In terms of the learning strategy "Cognitive strategy," "Cognitive strategy: Understand in one's own words" was revealed as an effective learning strategy, much like "Self-efficacy: Useful," for the improvement of answer characteristics in Problems 1-(1), 1-(2), and 2. However, the answer characteristics for which the use of "Cognitive strategy: Understand in one's own words" is revealed as effective are "Understanding of probability definition," "Understanding definition of conditional probability," and "Understanding definition of normalized constant," which implies that this strategy is effective for understanding definitions at the initial stage of learning. This contrasts with "Self-efficacy: Useful," which is effective in promoting further improvement after a given learner understands the basics required to solve problems. "Cognitive strategy: Identification of content" was shown as effective for "Notation" in Problem 2, "Aware object of proof" in Problem 4-(1), and "Correctness of second item calculation" in Problem 4-(2-2). "Aware object of proof" in Problem 4-(1) is a variable that represents the accurate awareness of the relationship between the binominal distribution and Poisson distribution, which is the object of the proof, and the association of learned contents is interpreted as a product of the application of the learning strategy to identify the content. 
Table 10. The Relationship Between Effective Learning Strategies And Answer Characteristics In The Midterm Examination

\begin{tabular}{|c|c|c|c|c|c|c|c|c|c|c|c|}
\hline & & & & & & Problem & & & & & \\
\hline & 1-(1) & $1-(2)$ & $1-(3)$ & $1-(4)$ & 2 & $3-(1)-1$ & $3-(1)-2$ & $3-(1)-3$ & 4-(1) & $4-(2-1)$ & $4-(2-2)$ \\
\hline $\begin{array}{l}\text { Self- } \\
\text { efficacy: } \\
\text { Useful }\end{array}$ & $\begin{array}{l}\text { Clearly } \\
\text { stated } \\
\text { reason of } \\
\text { judgment }\end{array}$ & $\begin{array}{c}\text { Correct } \\
\text { Numerical } \\
\text { calculation }\end{array}$ & & & $\begin{array}{c}\text { Correct } \\
\text { Numerical } \\
\text { calculation }\end{array}$ & & & & & & \\
\hline $\begin{array}{c}\text { Self- } \\
\text { efficacy: } \\
\text { Within the } \\
\text { scope of the } \\
\text { course }\end{array}$ & & & & & & $\begin{array}{l}\text { Aware of } \\
\text { object of } \\
\text { proof }\end{array}$ & $\begin{array}{c}\text { Understand } \\
\text { Properties } \\
\text { of } \\
\text { continuous } \\
\text { distribution }\end{array}$ & & & & \\
\hline $\begin{array}{c}\text { Self- } \\
\text { efficacy: } \\
\text { Outside the } \\
\text { scope of the } \\
\text { course }\end{array}$ & & & & & & & & $\begin{array}{l}\text { Understand } \\
\text { Properties } \\
\text { of } \\
\text { Normal } \\
\text { distribution }\end{array}$ & & & \\
\hline $\begin{array}{l}\text { Intrinsic value: } \\
\text { Important }\end{array}$ & $\begin{array}{c}\text { Accurate } \\
\text { notation } \\
\text { clearly } \\
\text { stated } \\
\text { reason of } \\
\text { judgment } \\
\end{array}$ & & & & & $\begin{array}{l}\text { Understand } \\
\text { properties } \\
\text { of } \\
\text { continuous } \\
\text { distribution }\end{array}$ & $\begin{array}{c}\text { Aware of } \\
\text { object of } \\
\text { proof }\end{array}$ & & & & \\
\hline $\begin{array}{l}\text { Intrinsic value: } \\
\text { Interesting }\end{array}$ & $\begin{array}{c}\text { Clearly } \\
\text { stated } \\
\text { reason of } \\
\text { judgment }\end{array}$ & $\begin{array}{l}\text { Understand } \\
\text { definition } \\
\text { of } \\
\text { conditional } \\
\text { probability } \\
\text { Accurate } \\
\text { reading of } \\
\text { the } \\
\text { distribution } \\
\text { table } \\
\end{array}$ & & & & & & & & & \\
\hline $\begin{array}{c}\text { Cognitive } \\
\text { strategy: } \\
\text { Understand in } \\
\text { one's own } \\
\text { words } \\
\end{array}$ & $\begin{array}{c}\text { Understand } \\
\text { definition } \\
\text { of } \\
\text { probability }\end{array}$ & $\begin{array}{l}\text { Understand } \\
\text { definition } \\
\text { of } \\
\text { conditional } \\
\text { probability }\end{array}$ & & & $\begin{array}{c}\begin{array}{c}\text { Understand } \\
\text { definition } \\
\text { of } \\
\text { normalized } \\
\text { constants }\end{array} \\
\end{array}$ & & & & & & \\
\hline $\begin{array}{c}\text { Cognitive } \\
\text { strategy: } \\
\text { Identification } \\
\text { of content } \\
\end{array}$ & & & & & $\begin{array}{l}\text { Accurate } \\
\text { notation }\end{array}$ & & & & $\begin{array}{c}\text { Aware of } \\
\text { object of } \\
\text { proof }\end{array}$ & & $\begin{array}{c}\text { Correct } \\
\text { second } \\
\text { item } \\
\text { calculation } \\
\end{array}$ \\
\hline $\begin{array}{l}\text { Cognitive } \\
\text { strategy: } \\
\text { Association } \\
\text { with one's } \\
\text { knowledge }\end{array}$ & & & & & $\begin{array}{c}\text { Complete } \\
\text { description } \\
\text { Accurate } \\
\text { reading of } \\
\text { prior } \\
\text { probability } \\
\end{array}$ & & & $\begin{array}{l}\text { Understand } \\
\text { properties } \\
\text { of normal } \\
\text { distribution }\end{array}$ & & & \\
\hline $\begin{array}{l}\text { Cognitive } \\
\text { strategy: } \\
\text { Repetitive } \\
\text { learning of key } \\
\text { concepts }\end{array}$ & & & $\begin{array}{c}\text { Understand } \\
\text { definition } \\
\text { of expected } \\
\text { values of } \\
\text { two } \\
\text { variables } \\
\end{array}$ & & & & & & $\begin{array}{l}\text { Aware of } \\
\text { object of } \\
\text { proof }\end{array}$ & & \\
\hline $\begin{array}{c}\text { Self- } \\
\text { regulation: } \\
\text { Comprehension } \\
\text { check }\end{array}$ & & & & $\begin{array}{c}\text { Understand } \\
\text { definition } \\
\text { of variance } \\
\text { of two } \\
\text { variables }\end{array}$ & & & $\begin{array}{l}\text { Aware of } \\
\text { object of } \\
\text { proof }\end{array}$ & & $\begin{array}{l}\text { Understand } \\
\text { Constraint } 1\end{array}$ & & \\
\hline $\begin{array}{c}\text { Self- } \\
\text { regulation: } \\
\text { Self- } \\
\text { directed } \\
\text { learning } \\
\end{array}$ & & $\begin{array}{l}\text { Accurate } \\
\text { notation }\end{array}$ & & & & & & & & & \\
\hline $\begin{array}{l}\text { Self- } \\
\text { regulation: } \\
\text { Rereading }\end{array}$ & & & & & & $\begin{array}{l}\text { Understand } \\
\text { properties } \\
\text { of } \\
\text { continuous } \\
\text { distribution } \\
\end{array}$ & $\begin{array}{c}\text { Complete } \\
\text { description }\end{array}$ & & & & \\
\hline $\begin{array}{c}\text { Self- } \\
\text { regulation: } \\
\text { Uninterested } \\
\text { topics } \\
\end{array}$ & & & & & & $\begin{array}{c}\text { Complete } \\
\text { description }\end{array}$ & & $\begin{array}{l}\text { Accurate } \\
\text { graphic } \\
\text { drawing }\end{array}$ & & & \\
\hline $\begin{array}{c}\text { Study habit: } \\
\text { Study with } \\
\text { similar } \\
\text { problems }\end{array}$ & & & & & & $\begin{array}{l}\text { Understand } \\
\text { calculation } \\
\text { rules }\end{array}$ & & & & & \\
\hline
\end{tabular}


Table 10 (continued). The Relationship Between Effective Learning Strategies And Answer Characteristics In The Mid-term Examination

\begin{tabular}{|c|c|c|c|c|c|c|c|c|c|c|c|c|}
\hline & \multicolumn{12}{|c|}{ Problem } \\
\hline & 1-(1) & $1-(2)$ & $1-(3)$ & $1-(4)$ & 2 & $3-(1)-1$ & $3-(1)-2$ & $3-(1)-3$ & $\begin{array}{r}3- \\
(2) \\
\end{array}$ & 4-(1) & $4-(2-1)$ & $4-(2-2)$ \\
\hline $\begin{array}{l}\text { Study time: } \\
\text { Central } \\
\text { position }\end{array}$ & & & & & & & & & & & $\begin{array}{l}\text { Understand } \\
\text { definition } \\
\text { of } \\
\text { probability } \\
\text { function } \\
\end{array}$ & $\begin{array}{c}\text { Correct } \\
\text { first item } \\
\text { calculation }\end{array}$ \\
\hline $\begin{array}{l}\text { Study time: } \\
\text { Dispersion }\end{array}$ & & & $\begin{array}{c}\text { Correct } \\
\text { numerical } \\
\text { calculation }\end{array}$ & & $\begin{array}{c}\text { Accurate } \\
\text { reading of } \\
\text { conditional } \\
\text { probability } \\
\end{array}$ & & $\begin{array}{l}\text { Understand } \\
\text { definition } \\
\text { of variance }\end{array}$ & & & & & \\
\hline $\begin{array}{l}\text { Study time: } \\
\text { Probability } \\
\text { distribution }\end{array}$ & & & & & & & & $\begin{array}{c}\text { Understand } \\
\text { properties } \\
\text { of normal } \\
\text { distribution } \\
\end{array}$ & & $\begin{array}{c}\text { Correct } \\
\text { distribution } \\
\text { formula } \\
\text { manipulation }\end{array}$ & $\begin{array}{c}\text { Accurate } \\
\text { notation }\end{array}$ & \\
\hline $\begin{array}{l}\text { References: } \\
\text { Probability } \\
\text { and statistics }\end{array}$ & & & & & & & & & & & $\begin{array}{c}\text { Accurate } \\
\text { reading of } \\
\text { distributed } \\
\text { information } \\
\end{array}$ & \\
\hline $\begin{array}{c}\text { References: } \\
\text { Outside } \\
\text { probability } \\
\text { and statistics }\end{array}$ & & & & & & & $\begin{array}{c}\text { Complete } \\
\text { description }\end{array}$ & & & & & \\
\hline $\begin{array}{l}\text { Web- } \\
\text { based } \\
\text { material }\end{array}$ & & $\begin{array}{l}\text { Understand } \\
\text { definition } \\
\text { of } \\
\text { conditional } \\
\text { expectation } \\
\end{array}$ & & & & & & & & $\begin{array}{c}\text { Complete } \\
\text { description }\end{array}$ & & \\
\hline $\begin{array}{c}\text { Other course } \\
\text { materials or } \\
\text { materials from } \\
\text { other } \\
\text { universities } \\
\end{array}$ & & & & & & & & & & & & $\begin{array}{c}\text { Understand } \\
\text { definition } \\
\text { of discrete } \\
\text { distribution } \\
\text { probability } \\
\end{array}$ \\
\hline
\end{tabular}

As for the learning strategy "Self-regulation," "Self-regulation. Comprehension check" is considered an effective learning strategy for a range of answer characteristics, including "Understanding definition of variance of two variables" in Problem 1-(4), which mainly deals with the expected value and variance of two variables, "Aware object of proof" in Problem 3-(1)-2; which relates to the probability distribution and "Understanding constraint 1" in Problem 4-(1).

Of all 4 learning strategy variables that express the study time, "Study time: Dispersion" and "Study time: Probability distribution" were extracted for a range of answer characteristics, the study time indicating that for dispersion and probability distribution was essential. Problems 3 and 4, which deal with probability distribution, are the problems for which "Study time: Probability distribution" was extracted as an effective learning strategy, demonstrating that study time directly affects the understanding of the subject matter. Conversely, "Study time: Dispersion" was extracted for Problem 1-(3), which is a calculation of the expected values of two variables, for Problem 2 on the Bayesian theorem, and for Problem 3-(1)-2, which mainly deals with variance. This highlights the particular importance of study time for dispersion in the study of probability and statistics.

\section{Learning Strategy Extraction for Qualitative Improvement of Learning in the Final Examination}

Regarding the Bayesian model used for the final examination, the constraints imposed on the model structure are explained below. Similar to the case of the mid-term examination, since the type of models with an edge structure in which the answer characteristic variable occupies the parent node and the learning strategy variable occupies the child node were deemed inappropriate, constraints were imposed on all answer characteristic variables by disallowing them from having learning strategy variables as their child nodes. Moreover, regarding the learning strategy variables, constraints were imposed on the "Study time: Statistical estimation" and "Study time: Statistical testing" for the study content learned in the second half such that they could not possess "Study time: Central position," "Study time: Dispersion," "Study time: Probability distribution," and "Study time: Relationship between variables" of mid-term examination topics as their child nodes.

Here, the results of extracting the learning strategies to improve the answer characteristics in Problem 1(1) (maximum likelihood estimate) are shown as an example. 


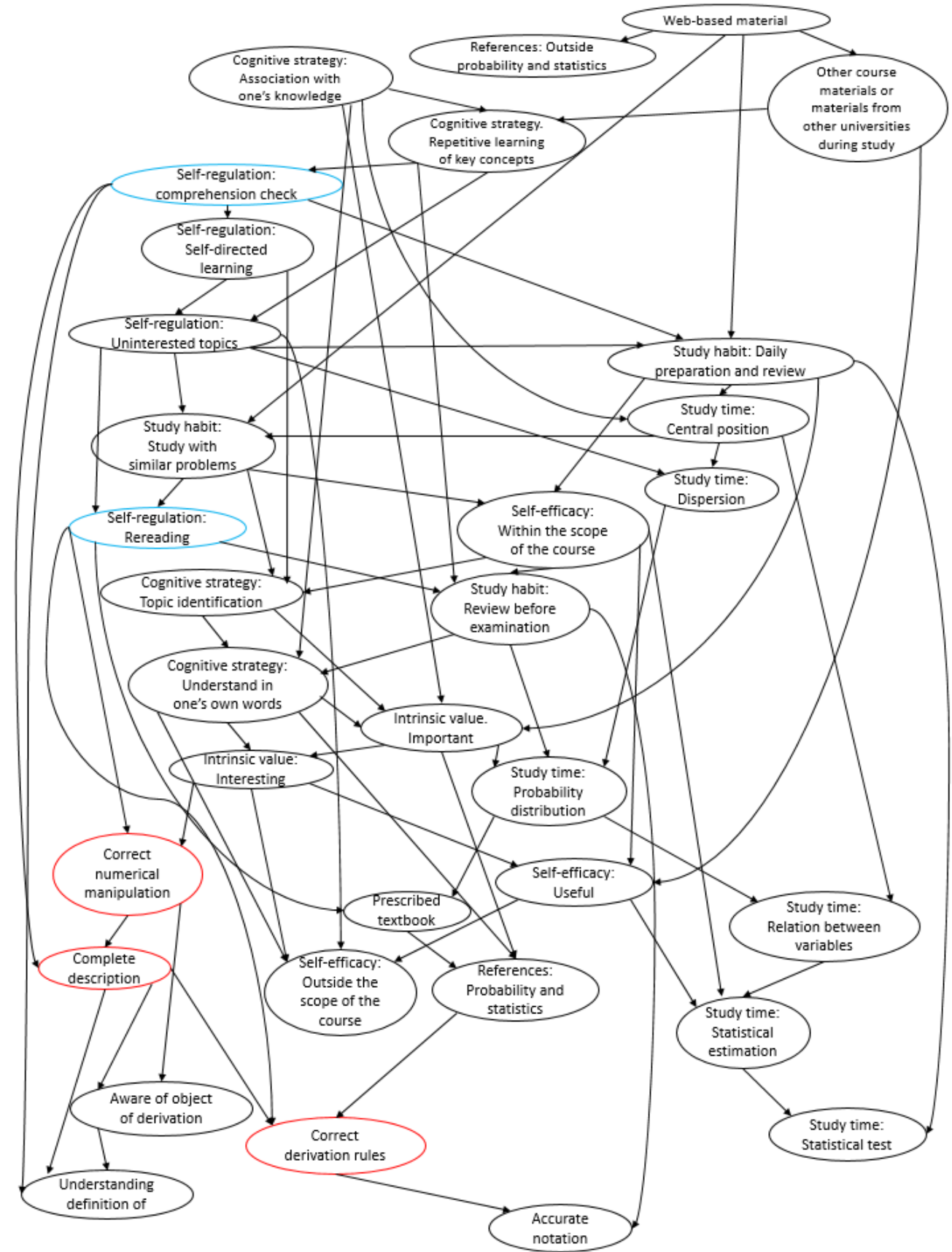

Figure 12. Structuration of a Bayesian Network for Answer Characteristics and Learning Strategies of Problem 1-(1)

Of all the pairs of nodes that were observed to have a direct, probabilistic dependence relationship from the learning strategy variable to the answer characteristic variable, those with a positive relationship are shown in Table 11. Regarding "Complete description," which expresses the completeness of the description for derivation, the importance of "Self-regulation. Comprehension check," that is, the importance of pursuing learning while checking one's comprehension, was suggested $(\mathrm{D}=0.180)$. Regarding "Correct formula manipulation," which expresses correct formula manipulation during the process of derivation, and "Understanding derivation rules," which expresses the learner's proper understanding of the derivation rules, "Self-regulation. Rereading," i.e., pursuit of learning by reviewing what has been learned (D=0.128, 0.222) was found to be important. 
Table 11. Difference between Conditional Probabilities at Edges that were Observed to have Direct, Probabilistic Dependence Relationships with the Answer Characteristic Variables

\begin{tabular}{ccc}
\hline Learning strategy variable $\mathbf{X}$ & Answer characteristic variable $\mathbf{Y}$ & $\mathbf{D}=\mathbf{P}(\mathbf{Y = 1} \mid \mathbf{X}=\mathbf{1}, \mathbf{M})-\mathbf{P}(\mathbf{Y}=\mathbf{1} \mid \mathbf{X}=\mathbf{0}, \mathbf{M})$ \\
\hline Self-regulation. Comprehension check & Complete description & 0.180 \\
\hline Self-regulation. Rereading & Correct formula manipulation & 0.128 \\
\hline Self-regulation. Rereading & Understanding derivation rules & 0.222 \\
\hline
\end{tabular}

Table 12 shows that the learning strategy "Self-efficacy: Outside the scope of the course" was effective for "Complete description" in Problem 1-(2-2), and "Description of Distribution that the statistic follow to," "Understanding definition of confidence interval," and "Accurate reading of percentage points in t-distribution" in Problem 3. Seen from each Problem, this is considered important primarily for the understanding of statistical estimation. Problems 1-(2-2) and 3-(1) are shown as effective for answer characteristics concerning description, which are therefore thought to comprise an important strategy for devising complete expressions.

The learning strategy "Cognitive strategy: Identification of content" is shown as effective for the answer characteristics in Problem 1-(2-1), which is concerned with unbiased estimates, Problem 2-(1), which is concerned with the concept of a two-sided test, and Problem 4-(1), for testing the equality of variance. By contrast, "Cognitive strategy: Association with one's knowledge" was shown as effective in improving answer characteristics in Problems 2-(1) and 4-(2), both of which are concerned with the testing of the hypothesis. Unlike "Cognitive strategy: Identification of content," it is considered effective for answer characteristics on relatively basic matters such as "Understanding definition of error in two-sided test," and "Understanding definition of test statistics." "Cognitive strategy: Repetitive learning of key concepts" is considered an effective strategy across a wide range of questions, including "Understanding definition of Chebyshev's inequality" in Problem 1-(2-3), "Understanding definition of two-sided test," "Understanding definition of one-sided test" in Problems 2-(1) and (2), and "Aware of object of derivation" in Problem 3-(1).

Of the six learning strategy variables for study time, the study time for contents in the Central position, Dispersion, and Probability distribution, which were learned before the mid-term exam, and the study time

Table 12. The Correspondence between the Effective Learning Strategies and Answer Characteristics in the Final Examination

\begin{tabular}{|c|c|c|c|c|c|c|c|c|c|c|c|}
\hline & & & & & & Problem & & & & & \\
\hline & 1-(1) & $1-(2-1)$ & $1-(2-2)$ & $1-(2-3)$ & $2-(1)$ & $2-(2)$ & $3-(1)$ & $3-(2)$ & $3-(3)$ & 4-(1) & 4-(2) \\
\hline $\begin{array}{c}\text { Self- } \\
\text { efficacy: } \\
\text { Within the } \\
\text { scope of the } \\
\text { course } \\
\end{array}$ & & & & $\begin{array}{l}\text { Accurate } \\
\text { notation }\end{array}$ & & & & & & & \\
\hline $\begin{array}{l}\text { Self- } \\
\text { efficacy: } \\
\text { Outside the } \\
\text { scope of the } \\
\text { course }\end{array}$ & & & $\begin{array}{c}\text { Complete } \\
\text { description }\end{array}$ & & & & $\begin{array}{c}\text { Description } \\
\text { of } \\
\text { Distribution } \\
\text { that the } \\
\text { statistic } \\
\text { follows } \\
\end{array}$ & $\begin{array}{l}\text { Understanding } \\
\text { definition of } \\
\text { confidence } \\
\text { interval }\end{array}$ & $\begin{array}{l}\text { Accurate } \\
\text { reading of } \\
\text { percentage } \\
\text { points in t- } \\
\text { distribution }\end{array}$ & & \\
\hline $\begin{array}{l}\text { Cognitive } \\
\text { strategy: } \\
\text { Understand in } \\
\text { one's own } \\
\text { words }\end{array}$ & & & & & & & & & & $\begin{array}{l}\text { Understanding } \\
\text { how to } \\
\text { calculate } \\
\text { percentage } \\
\text { points in F } \\
\text { distribution }\end{array}$ & \\
\hline $\begin{array}{l}\text { Cognitive } \\
\text { strategy: } \\
\text { Identification } \\
\text { of content }\end{array}$ & & $\begin{array}{l}\text { Accurate } \\
\text { notation }\end{array}$ & & & $\begin{array}{c}\text { Correct } \\
\text { graphical } \\
\text { demonstration } \\
\text { of errors of } \\
\text { test }\end{array}$ & & & & & $\begin{array}{l}\text { Understanding } \\
\text { definition of } \\
\text { confidence } \\
\text { interval }\end{array}$ & \\
\hline $\begin{array}{c}\text { Cognitive } \\
\text { strategy: } \\
\text { Association } \\
\text { with one's } \\
\text { knowledge } \\
\end{array}$ & & & & & $\begin{array}{l}\text { Understanding } \\
\text { definition of } \\
\text { errors in two- } \\
\text { sided test }\end{array}$ & & & & & & $\begin{array}{l}\text { Understanding } \\
\text { definition of } \\
\text { testing } \\
\text { statistics }\end{array}$ \\
\hline $\begin{array}{c}\text { Cognitive } \\
\text { strategy: } \\
\text { Repetitive } \\
\text { learning of key } \\
\text { concepts } \\
\end{array}$ & & & & $\begin{array}{l}\text { Understanding } \\
\text { Chebyshev's } \\
\text { inequality }\end{array}$ & $\begin{array}{l}\text { Understanding } \\
\text { definition of } \\
\text { errors in two- } \\
\text { sided test }\end{array}$ & $\begin{array}{l}\text { gunderstanding } \\
\text { definition of } \\
\text { errors in one- } \\
\text { sided test }\end{array}$ & $\begin{array}{l}\text { Aware of } \\
\text { object of } \\
\text { derivation }\end{array}$ & & & & \\
\hline $\begin{array}{c}\text { Self- } \\
\text { regulation: } \\
\text { Comprehension } \\
\text { check } \\
\end{array}$ & $\begin{array}{c}\text { Complete } \\
\text { description }\end{array}$ & & & & & $\begin{array}{c}\text { Correct } \\
\text { graphical } \\
\text { demonstration } \\
\text { of power }\end{array}$ & & & & & \\
\hline $\begin{array}{c}\text { Self- } \\
\text { regulation: } \\
\text { Self- } \\
\text { directed } \\
\text { learning } \\
\end{array}$ & & & & & & & & & $\begin{array}{c}\text { Correct } \\
\text { numerical } \\
\text { calculation }\end{array}$ & & \\
\hline
\end{tabular}


Table 12 (continued). The Correspondence between the Effective Learning Strategies and Answer Characteristics in the Final Examination

\begin{tabular}{|c|c|c|c|c|c|c|c|c|c|c|c|}
\hline & & & & & & roblem & & & & & \\
\hline & 1-(1) & 1-(2-1) & 1-(2-2) & 1-(2-3) & $2-(1)$ & $2-(2)$ & $3-(1)$ & $3-(2)$ & $3-(3)$ & 4-(1) & 4-(2) \\
\hline $\begin{array}{l}\text { Self- } \\
\text { regulation: } \\
\text { Rereading }\end{array}$ & $\begin{array}{c}\text { Correct } \\
\text { formula } \\
\text { manipulation } \\
\text { Correct } \\
\text { derivation } \\
\text { rules } \\
\end{array}$ & $\begin{array}{c}\text { Understanding } \\
\text { definition of } \\
\text { expected value }\end{array}$ & & & & & & & & & \\
\hline $\begin{array}{c}\text { Study habit: } \\
\text { Daily } \\
\text { preparation } \\
\text { and review } \\
\end{array}$ & & & & & & $\begin{array}{c}\text { Correct } \\
\text { graphical } \\
\text { demonstration } \\
\text { of errors of test }\end{array}$ & & & & & \\
\hline $\begin{array}{c}\text { Study habit: } \\
\text { Study with } \\
\text { similar } \\
\text { problems }\end{array}$ & & & $\begin{array}{c}\text { Explaining } \\
\text { grounds for } \\
\text { minimum } \\
\text { variance } \\
\text { Aware of } \\
\text { object of proof }\end{array}$ & & & & & & & $\begin{array}{l}\text { Understanding } \\
\text { definition of } \\
\text { errors in two- } \\
\text { sided test }\end{array}$ & $\begin{array}{l}\text { Accurate } \\
\text { reading of } \\
\text { percentage } \\
\text { points in } t- \\
\text { distribution }\end{array}$ \\
\hline $\begin{array}{l}\text { Study time: } \\
\text { Central } \\
\text { position }\end{array}$ & & & & & & $\begin{array}{c}\text { Understanding } \\
\text { definition of } \\
\text { power in one- } \\
\text { sided test }\end{array}$ & & & & $\begin{array}{l}\text { Understanding } \\
\text { definition of } \\
\text { confidence } \\
\text { interval } \\
\end{array}$ & \\
\hline $\begin{array}{l}\text { Study time: } \\
\text { Dispersion }\end{array}$ & & & & & & & & $\begin{array}{c}\text { Aware of } \\
\text { object of } \\
\text { derivation }\end{array}$ & & $\begin{array}{l}\text { Clearly stated } \\
\text { test hypothesis }\end{array}$ & \\
\hline $\begin{array}{l}\text { Study time: } \\
\text { Probability } \\
\text { distribution }\end{array}$ & & & $\begin{array}{l}\text { Complete } \\
\text { description }\end{array}$ & & & & & & & & \\
\hline $\begin{array}{l}\text { Study time: } \\
\text { Statistical } \\
\text { estimation }\end{array}$ & & & $\begin{array}{c}\text { Correct } \\
\text { formula } \\
\text { manipulation }\end{array}$ & & $\begin{array}{c}\text { Understanding } \\
\text { situations where } \\
\text { power is } \\
\text { increased }\end{array}$ & $\begin{array}{l}\text { Understanding } \\
\text { definition of } \\
\text { errors in one- } \\
\text { sided test } \\
\end{array}$ & & & & & \\
\hline $\begin{array}{c}\text { Web- } \\
\text { based } \\
\text { material }\end{array}$ & & & & $\begin{array}{l}\text { Accurate } \\
\text { notation }\end{array}$ & & & $\begin{array}{l}\text { Aware of } \\
\text { object of } \\
\text { derivation }\end{array}$ & & & $\begin{array}{l}\text { Understanding } \\
\text { definition of } \\
\text { errors in two- } \\
\text { sided test } \\
\end{array}$ & $\begin{array}{c}\text { Understanding } \\
\text { definition of } \\
\text { pooled unbiased } \\
\text { variance } \\
\end{array}$ \\
\hline $\begin{array}{c}\text { Other course } \\
\text { materials or } \\
\text { materials } \\
\text { from other } \\
\text { universities } \\
\end{array}$ & & & & & $\begin{array}{c}\text { Correct } \\
\text { graphical } \\
\text { demonstration } \\
\text { of errors of test }\end{array}$ & & & & & & \\
\hline
\end{tabular}

for contents concerning statistical test, which were learned later, were confirmed as effective for improving the answer characteristics. "Study time: Statistical test" was observed as effective for Problem 1-(2-2), which deals with the minimum variance of estimator, and for "Understanding situations where power is elevated" and "Understanding definition of error in one-sided test," which are the answer characteristics of Problems 2(1) and (2), respectively, for the concept of testing a hypothesis. The study time spent on hypothesis testing is therefore considered particularly effective for understanding the testing errors, which comprise one of the most fundamental issues in hypothesis test.

Regarding the learning strategy variables of the study materials used, the "Web-based material" was revealed as effective across a range of questions, including Problems 1-(2-3), 3-(1), 4-(1), and 4-(2).

\section{Learning Strategy Extraction using Individual Probabilistic Reasonings based on the Bayesian Network Model}

As a next step, a probabilistic reasoning conditioned on the comprehension of each learner and his use of a given learning strategy was performed individually, to quantitatively assess any learning improvements that may prove effective for learner. Here, suppose that a learner $i$ fails to correctly answer the question $q$ in

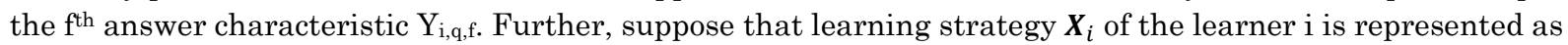

$$
\boldsymbol{X}_{i}=\left[x_{i, 1}, \ldots, x_{i, m-1}, 0, x_{i, m+1}, \ldots, x_{i, r}\right]
$$

and element $X_{i, m}$ of the learning strategy is 0 . In addition, let answer characteristics other than f-th answer characteristic $\mathrm{Y}_{\mathrm{i}, \mathrm{q}, \mathrm{f}}$ of the learner $\mathrm{i}$ be expressed as

$$
\boldsymbol{Y}_{i, q}(-f)=\left[Y_{i, q, 1}, \ldots, Y_{i, q, f-1}, Y_{i, q, f+1}, \ldots, Y_{i, q, p}\right]
$$

Then, the probability that the learner i will correctly answer the f-th answer characteristic $\mathrm{Y}_{\mathrm{i}, \mathrm{q}, \mathrm{f}}$ under the learning strategy he or she has currently adopted can be expressed as

$$
P\left(Y_{i, q}, f=1 \mid X_{i}, \quad Y_{i, q}=(-f)\right)
$$


Table 13. Results of Probabilistic Reasonings for Student 07

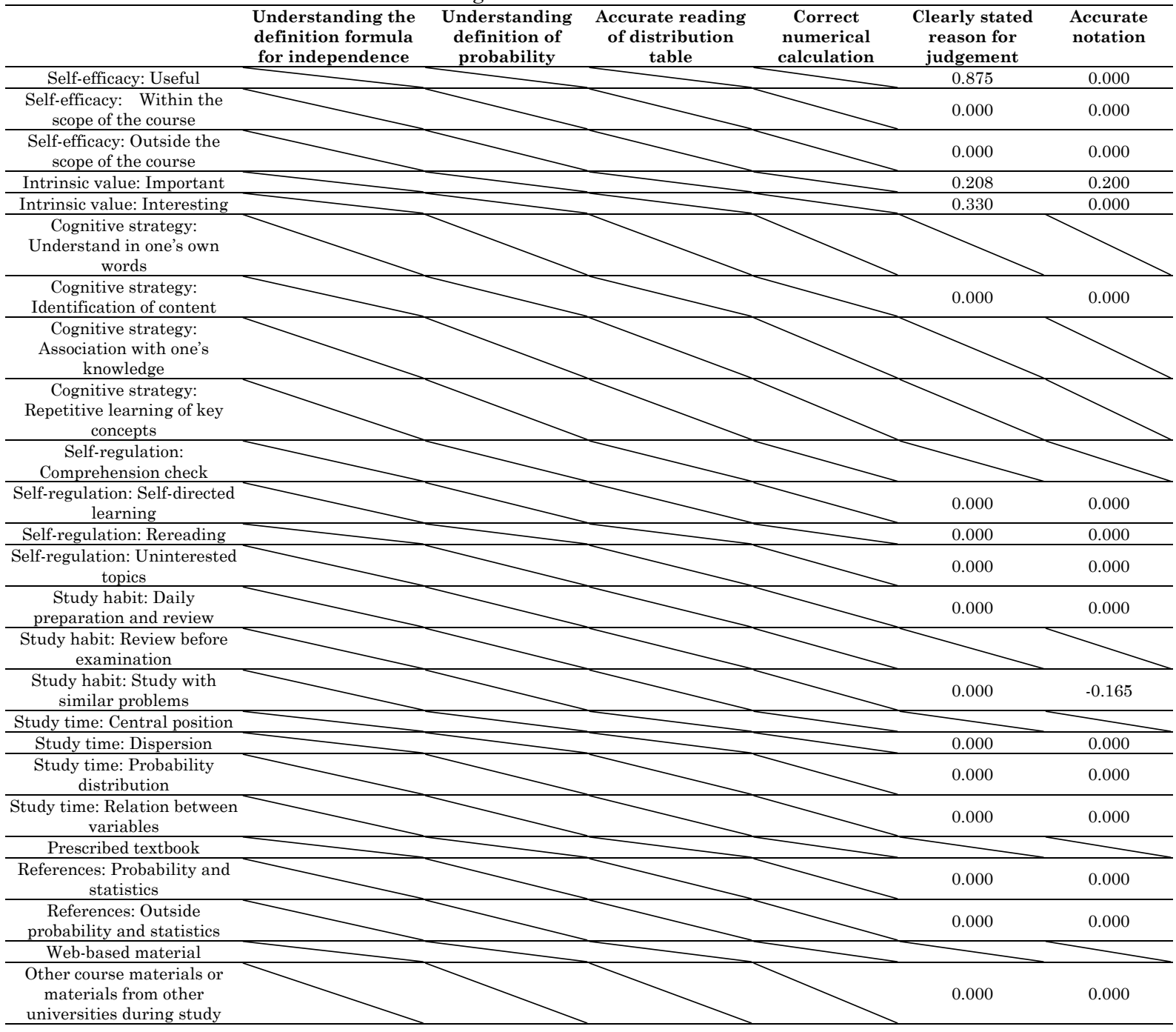

Here, if learner $\mathrm{i}$ improves the element $X_{i, m}$ of the learning strategy and the learning strategy at this point is expressed as $\boldsymbol{X}_{i}^{\prime}\left(x_{i, m}=1\right)$, then we obtain

$$
X_{i}^{\prime}=\left[x_{i, 1}, \ldots, x_{i, m-1}, 1, x_{i, m+1}, \ldots, x_{i, r}\right]
$$

and the probability that learner $i$ will correctly answer the $\mathrm{f}$-th answer characteristic $\mathrm{Y}_{\mathrm{i}, \mathrm{q}, \mathrm{f}}$ under the condition that he or she improved on the $\mathrm{m}$-th learning strategy is as follows.

$$
P\left(Y_{i, q, f}=1 \mid X i^{\prime}\left(x_{i, m}=1\right), \quad Y_{i, q}=(-f)\right)
$$

Then, if we take the difference between formulas (10) and (8)

$$
P\left(Y_{i, q, f}=1 \mid X i^{\prime}\left(x_{i, m}=1\right), \quad Y_{i, q}=(-f)\right)-P\left(Y_{i, q, f}=1 \mid X_{i}, \quad Y_{i, q}=(-f)\right)
$$

then the learning strategy $\mathrm{m}$, which is effective for improving the element $f$ of the learning characteristic in which learner $\mathrm{i}$ is interested, would be detected and assessed.

From the mid-term examination, an example of results related to probabilistic reasoning given changes tailored for a learner in the conditions of the learning strategy and answer characteristic parameters is shown in Table 13. Since the learning strategies that had already been used and answer variables that the learner had gotten right did not require improvement, diagonal lines were drawn in the relevant cells.

Student 07 failed to answer "Clearly stated reason of judgment" and "Correctness of notation" correctly. The probability that this student will give a correct answer for "Clearly stated reason of judgment" correctly with the current learning strategy and level of comprehension is expected to increase by approximately 0.875 
Table 14. Results of Probabilistic Reasonings for Student 12

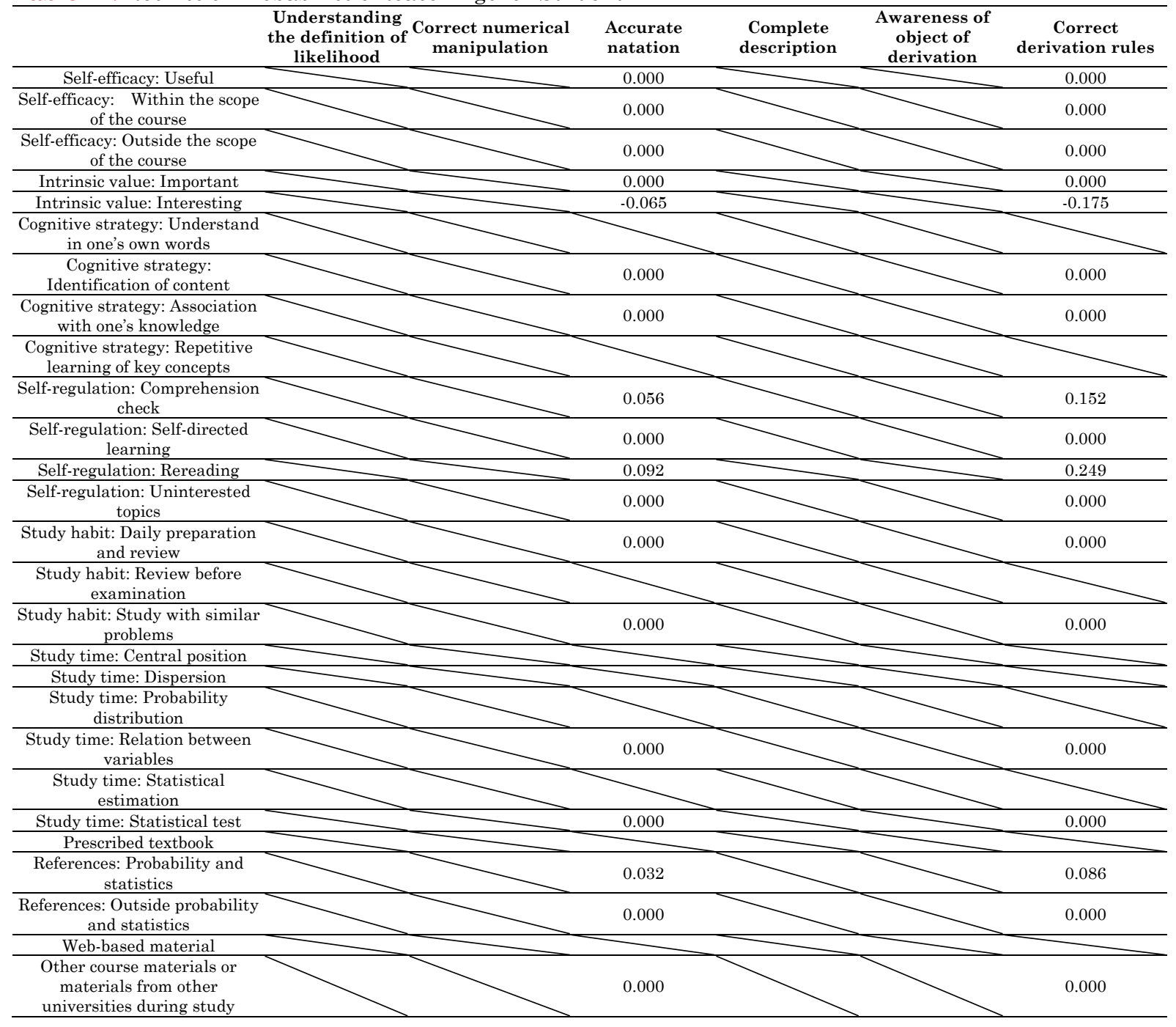

with improvement in "Self-efficacy: Useful," by approximately 0.208 with improvement in "Intrinsic value: Important," by approximately 0.300 with improvement in "Intrinsic value: Interesting." Moreover, the probability that he will give a correct answer for "Accurate notation" is expected to increase by about 0.2 , with an improvement in "Intrinsic value: Important."

The example of the final examination is shown in Table 14.

Student 12 failed to give a correct answer for "Accurate notation" and the "Correctness of derivation rules." The probability that this student will give a correct answer for "Accurate notation" and the "Correctness of derivation rules" under the current learning strategy and level of comprehension is expected to increase by approximately 0.056 and 0.152 , respectively, with improvements in "Self-regulation. Comprehension check," and by approximately 0.092 and 0.249 with improvements in "Self-regulation. Rereading," by approximately 0.032 and 0.086 , with the supportive use of "References: Probability and Statistics."

\section{SUMMARY}

This study propose the method to make variables of the level of comprehension of learners as answer characteristics in a class of probability and statistics based on actual student mistakes in answers to full descriptive questions; and an analytical method was proposed and examined that aimed to qualitatively improve learners' skills by giving feedback to both the educators and the learners. First, the method of making variables of answer characteristics from errors of answers in the mid-term and final examinations in probability and statistics was proposed and examined. Second, a regression tree analysis was conducted to 
extract answer characteristics that depict learners' level of comprehension for each question, in addition to providing a possible study policy to improve comprehension of the question for learners. Furthermore, item characteristic charts were used to visualize the relationship between comprehensive ability and the answer characteristics and a comprehensive analysis of learner comprehension levels requiring improvement was carried out to provide feedback for educators. Additionally, the relationship between the students' learning strategy and the answer characteristic was structured for each question using a BN model, and learning strategies effective for qualitative improvement in comprehension for both learners as a whole and as individuals were extracted and evaluated. Our findings suggested the presences of effective learning strategies separately for each concept in each question, as well as for each level of expertise, whether it was basic (understanding definition, etc.) or applied (Aware object of derivation, Complete description, etc.), in answer characteristics. This indicates that a learning strategy's importance differs according to the learning stage. Furthermore, improvement in dispersion based on study time was revealed to be effective in a wide range of questions in both the mid-term and final examinations.

\section{Disclosure statement}

No potential conflict of interest was reported by the authors.

\section{Notes on contributors}

Michiko Tsubaki - The University of Electro-Communications, Japan.

Wataru Ogawara - The University of Electro-Communications, Japan.

Kenta Tanaka - The University of Electro-Communications, Japan.

\section{REFERENCES}

Akiyama, T., Toyota, H., \& Iwama, T. (2015). Combing trace line of distractors on the basis of a hypothesis and a method to verify it in an error analysis using an item characteristics chart. Kansei Engineering, 14(3), 443-455. https://doi.org/10.5057/jjske.TJSKE-D-14-00081

Chen, J., Feng, J., Hu, J., \& Sun, X. (2019). Causal analysis of learning performance based on Bayesian network and mutual information. Entropy, 21(11), 1102-1136. https://doi.org/10.3390/e21111102

Durkin, K., \& Rittle-Johnson,B. (2012). The effectiveness of using incorrect examples to support learning about decimal magnitude. Learning and Instruction, 206-214. https://doi.org/10.1016/j.learninstruc.2011.11.001

Kahneman, D., \& Tversky, A. (1982). On the study of statistical intuitions. Cognition, 11(2), 123-141. https://doi.org/10.1016/0010-0277(82)90022-1

Lqbal, K., Yin, X., Hao, H., Ilyas, Q. M., \& Ali, H. (2015). An Overview of Bayesian Network Applications in Uncertain Domains. International Journal of Computer Theory and Engineering, 7(6), 416-427. https://doi.org/10.1007/978-1-4899-7687-7_717

Pintrich, P. R., \& De Groot, E. V. (1990). Motivational and self-regulated learning components of classroom academic performance. Journal of Educational Psychology, 82(1), 33-40. https://doi.org/10.1037/00220663.82.1.33

Rushton, S. J. (2018). Teaching and learning mathematics through error analysis. Fields Mathematics Education Journal, 1(1), article number 3. https://doi.org/10.1186/s40928-018-0009-y

Scutari, M., \& Denis, J. (2014). Bayesian Networks with Examples in R, New York: Chapman and Hall/CRC. https://doi.org/10.1201/b17065

Sulistyani, N. (2019). Error analysis in solving inferential statistics problems for psychology students. Journal of Physics: Conference Series, 1180 012006. https://doi.org/10.1088/1742-6596/1180/1/012006

Targo, L. (2017). "Regression Trees," In Sammut, C. and Webb,G.I.(eds.), Encyclopedia of Machine Learning and Data Mining, Springer, Boston, MA. https://doi.org/10.1007/978-1-4899-7687-1_717 


\section{APPENDIX}

\section{1) Mid-term Examination}

Problem 2:

Suppose that there are four AI (artificial intelligence) robots (A, B, C and D) that deliver some services. The $\mathrm{AI}$ robots A, B, C and D deliver $20 \%, 25 \%, 25 \%$ and $30 \%$ of the entire services respectively and out of services they deliver, they are empirically known to carry out inadequate services at $3 \%, 3 \%, 2 \%$ and $1 \%$ each. When sampling just one service out of the entire services, calculate the probability that it is an inadequate service.

Furthermore, when it is found to be inadequate, calculate the probability that the service was carried out by the AI robot D (Round up to 4 decimal places).

Question 3:

(1) Calculate the mean and variance of the random variable $X$ that obeys the normal distribution $N(\mu, \sigma 2)$. In addition, find the distribution function of this normal distribution. Note that the probability density function for the normal distribution $N(\mu, \sigma 2)$ is as follows.

$$
f(x)=\frac{1}{\sqrt{2 \pi \sigma}} e^{-\frac{(x-\mu)^{2}}{2 \sigma^{2}}}
$$

(2) Calculate $\mathrm{P}$ (formula omitted) for the random variable $\mathrm{X}$ that follows the normal distribution $\mathrm{N}(\mu, \sigma 2)$. (Round up to 4 decimal places.) The standard normal distribution table is shown in the right page.

\section{Question 4:}

(1) Prove that the Poisson distribution is an extreme distribution of binomial distribution. That is, in the binomial distribution $\{\mathrm{b}(\mathrm{k} ; \mathrm{n}, \mathrm{p})\}$, when $\mathrm{n} \rightarrow \infty$ while keeping $\mathrm{np}=\lambda(\lambda:$ constant $)$ constant, prove that the following obtains.

$$
b(k ; n, p) \rightarrow p(k ; \lambda)
$$

Here, the probability distribution of the binomial distribution $\{\mathrm{b}(\mathrm{k} ; \mathrm{n}, \mathrm{p})\}$ can be expressed as

$$
P(X=k)=b(k ; n, p)=\left(\begin{array}{l}
n \\
k
\end{array}\right) p^{k} q^{n-k}(k=0,1,2, \ldots, n)
$$

Likewise, the probability distribution of the Poisson distribution $\{\mathrm{p}(\mathrm{k} ; \lambda)\}$ can be expressed as

$$
p(k ; \lambda)=e^{-\lambda} \frac{\lambda^{k}}{k !}(k=0,1,2, \ldots ; \lambda>0)
$$

(2) In a service delivery field, services are carried out 100 times a day, of which about $2 \%$ are inadequate services.

$(2-1)$ In this service field, suppose that the number of inadequate services for tomorrow is $\mathrm{Y}$, Y follows $\mathrm{b}(\mathrm{k} ; 100,0.02)$. Find the probability function of this binomial distribution.

(2-2) Suppose that $\mathrm{Y}$ follows a Poisson distribution where $\lambda=n p=2$, calculate $\mathrm{P}(0 \leq \mathrm{Y} \leq 1)$. Round up to 3 decimal places. Note that $\mathrm{e}-2=0.135$. 


\section{2) Final examination}

Question 2:

(1) Explain the Type I error and Type II error, as well as power in case of a two-sided test in testing a statistical hypothesis using drawing too. Further, explain briefly the kinds of situations where power is elevated.

(2) Explain the Type I error and Type II error, as well as power in case of a one-sided test in testing a statistical hypothesis using drawing too.

Problem 3: When services made by an AI robot was randomly chosen and examined, the service duration was as follows.

10.510 .911 .110 .710 .8

Suppose that these service durations follow with the normal distribution $\mathrm{N}\left(\mu, \sigma^{2}\right)$, answer the following questions.

Note that in this case, both the mean $\mu$ and variance $\sigma^{2}$ are unknown.

(1) Show how to lead the confidence interval $\left(\hat{\mu}_{L}, \hat{\mu}_{U}\right)$ of the mean $\mu$, where the confidence coefficient is $\beta$.

(2) Calculate the $95 \%$ confidence interval of the variance $\sigma^{2}$.

(3) Calculate the $95 \%$ confidence interval of the mean $\mu$.

Refer to the distribution table shown in the right page.

\section{Problem 4}

In a soccer world cup, the average goal attempts per game was 15.1915 and the SD was 2.7312 for 16 top teams that advanced into the final tournament, while it was 12.2708 and 3.0773 respectively for 16 teams that failed to advance into the final tournament. Suppose that the total number of goal attempts per game for 16 teams that advanced into the final and for 16 teams that failed to do so follow $\mathrm{N}\left(\mu_{A}, \sigma_{A}^{2}\right), \mathrm{N}\left(\mu_{B}, \sigma_{B}^{2}\right)$.

(1) Perform a two-sided test for equality of $\left(\sigma_{A}^{2}=\sigma_{B}^{2}\right)$ of two population variances (significance level $=5 \%$ ).

(2) According to the test result of (1), perform a one-sided test on the difference in the population means (significance level $=5 \%$ )

Note that $\mathrm{F}_{15}^{15}(0.025)=2.862$ and refer to the distribution table shown in the right page. 